\title{
Small-scale turbulence and vertical mixing in Lake Baikal
}

\author{
Thomas M. Ravens, Otti Kocsis, and Alfred Wüest
}

Swiss Federal Institute for Environmental Science and Technology (EAWAG) and Swiss Federal Institute of Technology (ETH), CH-8600 Dübendorf, Switzerland

\section{N. Granin}

Limnological Institute of the Siberian Division of the Russian Academy of Sciences, P.O. Box 4199, Irkutsk 664033, Russia

\begin{abstract}
The water column of Lake Baikal is extremely weakly_but permanently-stratified below $250 \mathrm{~m}$. Despite the thickness of this relatively stagnant water mass of more than $1000 \mathrm{~m}$, the water age (time since last contact with the atmosphere) is only slightly more than a decade, indicating large-scale advective exchange. In the stratified deep water, the fate of water constituents is determined by the combined action of advective processes (deep-water intrusions) and small-scale turbulent vertical diffusion.

Here, vertical diffusivity is addressed through the analysis of 25 temperature microstructure profiles collected in the three major basins of Lake Baikal to a depth of $600 \mathrm{~m}$. In addition, in the 1,432-m deep south basin, monthly CTD profiles and a two year record of near-bottom currents were analyzed. Balancing turbulent kinetic energy and small-scale temperature variance leads to the conclusions that (1) vertical diffusivity in the stratified deep water ranges from 10-90 $\times 10^{-4} \mathrm{~m}^{2} \mathrm{~s}^{-1}$ (between 600 and $250 \mathrm{~m}$ ), which is three orders of magnitude more than estimated by Killworth et al. (1996), (2) the mixing efficiency is $\sim 0.16$, comparable to that found in stronger stratification (e.g., the ocean interior), (3) turbulence under ice decays with a time scale of $40 \pm 2 \mathrm{~d}$ and (4) the interior of the permanently stratified deep water below $250 \mathrm{~m}$ and the bottom boundary layer contribute roughly equally to the TKE production. The latter implies, that mixing in the deep water of Lake Baikal's three sub-basins is dominated by bottom boundary mixing as found in smaller lakes and ocean basins.
\end{abstract}

Lake Baikal, located in the Great Baikal Rift zone in eastern Siberia, is by volume $\left(23,015 \mathrm{~km}^{3}\right)$ and by depth (maximum: $1,632 \mathrm{~m}$ ) the earth's largest freshwater body (Shimaraev et al. 1994). Since Lake Baikal is one of the oldest freshwater basins (Golubev et al. 1993) and because it faces extreme conditions, including several months of ice cover, large depth, a long water residence time $(\sim 350$ years $)$, and low nutrient concentration, it developed to a unique ecosystem, which gives habitat to more than 1,500 endemic species (Martin, 1994). Topographically, the lake consists of three main basins (south, middle, and north) which are formed by sills reaching up to about $300 \mathrm{~m}$ (Fig. 1). The south basin (maximum depth: 1,432 $\mathrm{m}$ ) is the main focus of this study.

As with most temperate natural waters, during the summer the vertical temperature gradient of Lake Baikal is positive throughout the entire water column leading to stable density stratification with surface temperature above $14^{\circ} \mathrm{C}$. Since the temperature of maximum density $\mathrm{T}_{\mathrm{md}}\left[{ }^{\circ} \mathrm{C}\right]$ of near-surface

\section{Acknowledgments}

We are indebted to Mike Schurter and Ruslan Gnadovsky for their help with the field campaign. We thank Michael Sturm and Rolf Kipfer for logistic and organizational support, the Swiss Federal office for Education and Science (BBW) for financial support, and Daniel Schenker for mathematical assistance in analysis of the velocity spectra. Current and thermister data were obtained during a 2-y mooring experiment on Geochemistry, Particle Formation and Sediment Sources (GEOPASS) funded by EAWAG and the British National Environmental Research Council (NERC). In addition, this work was supported by Swiss National Science Foundation grants 20-36'364.92, 2000-043’357.95 and 20-50761.97 and by BBW (MITEC). freshwater $\left(\sim 4^{\circ} \mathrm{C}\right)$ is significantly above $0^{\circ} \mathrm{C}$ and since the surface freezes during the cold season, the surface layer becomes inversely stratified with respect to temperature while stably stratified with respect to density. Therefore, the water column of Lake Baikal is characterized by a surface layer above $\sim 250 \mathrm{~m}$ (Peeters et al. 1996) and a permanently stratified deep water mass (PSDW) below. Periodically, the surface layer is density stratified (summer and winter) and subject to free convection due to near-uniform temperature (late spring and late fall), with the thickness of the surface layer depending on the rates of winter cooling and wind-induced mixing.

As a result of the thermal structure of Lake Baikal, the deep water is permanently and stably stratified. Therefore one would expect the water constituents to be exchanged by small-scale turbulent processes only. As the stably stratified water column is up to $\sim 1,400 \mathrm{~m}$ thick, the corresponding time scales for vertical exchange should be hundreds of years $\left[(1,400 \mathrm{~m})^{2} / 10^{-4} \mathrm{~m}^{2} \mathrm{~s}^{-1} \sim 600 \mathrm{yr}\right]$. It was a great surprise that deep water ages, determined independently from vertical distributions of tritium/helium (Craig 1989; Hohmann et al. 1998) as well as fluorochlorocarbons, CFCs (Weiss et al. 1991), showed time scales of only 10 to $18 \mathrm{yrs}$. The high oxygen concentration even at great depth (greater than $80 \%$ of saturation, Weiss et al. 1991), corroborate rapid deep water renewal. Profile maxima of CFCs and oxygen, sporadically found in the deepest layers of the three basins call for a large-scale advective deep water renewal down to maximum depth (Weiss et al. 1991; Shimaraev et al. 1993).

One way to quantify deep-water renewal is to identify and observe 'density-producing' processes. Density might be in- 


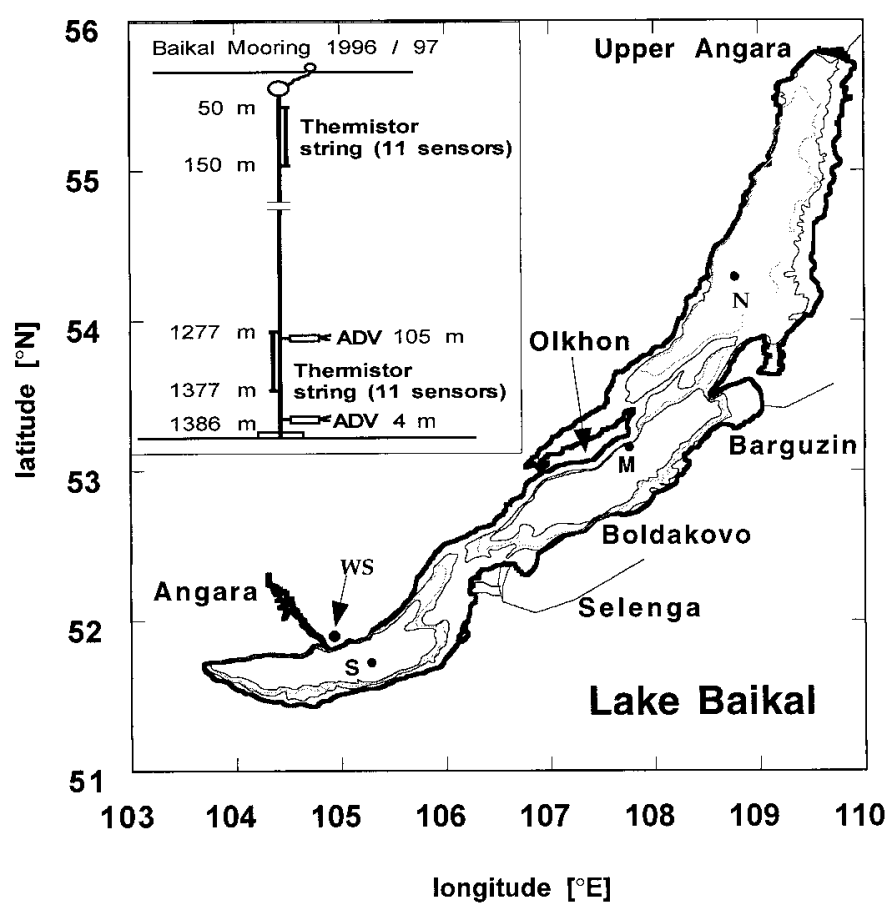

Fig. 1. Map of Lake Baikal. The three microstructure measurement stations ( $, M, N)$ in the south, middle, and north basin, as well as the wind station (WS) are indicated. Thermistor and ADV current meter data were collected at station $\mathrm{S}$. The inset displays the depth (height above bottom) of the two thermistor strings and the ADV current meter moored at S.

creased due to temperature (T) changes, salinity (S) increases, or due to the addition of particles or other water constituents (e.g., by Selenga River inflow; Hohmann et al. 1997). Deep-water renewal might also be caused by thermobaric instability subsequent to wind-induced vertical dislocation of surface water (Weiss et al. 1991; Carmack and Weiss, 1991; Killworth et al. 1996; Walker and Watts, 1995), or by non-linear effects under mixing of equally dense water with different T-S compositions (Peeters et al. 1996). However, there is no consensus yet on the relative importance of the various possible deep-water renewal mechanisms.

A complementary way to investigate deep-water renewal is to quantify vertical diffusivity, since it competes with large-scale advection in the vertical distribution of the different water constituents $\mathrm{C}_{\mathrm{i}}$. If large-scale deep water renewal occurs several times over decades, one can expect 'quasi'steady-state profiles $\mathrm{C}_{\mathrm{i}}(\mathrm{z})$ to build up (z: depth; positive upward). They reflect the advection-diffusion-reaction flux balance given by $\mathrm{w}(\mathrm{z}) \cdot \mathrm{C}_{\mathrm{i}}(\mathrm{z})-\mathrm{K}(\mathrm{z}) \cdot \partial \mathrm{C}_{\mathrm{i}}(\mathrm{z}) / \partial \mathrm{z}+\mathrm{F}_{\mathrm{S}, \mathrm{i}}(\mathrm{z})=0$, where $w(z)$ is the vertical upward velocity due to the input volume per area and $F_{S, i}$ is the flux of sources and sinks (e.g., oxygen consumption). Consequently vertical diffusivity K(z) contains information on deep water renewal. Such an approach has been used by Killworth et al. (1996), who developed an advection-diffusion-reaction model to investigate deep-water renewal. By fitting modeled concentration profiles of CFCs, oxygen, tritium and helium to their data, they obtained an upwelling rate of about $500 \mathrm{~km}^{3} \mathrm{a}^{-1}$ at 400 $\mathrm{m}$, and vertical turbulent diffusivity of order $10^{-6} \mathrm{~m}^{2} \mathrm{~s}^{-1}$.
Frank Peeters (pers. comm.), with a similar approach and the same type of tracers, has estimated vertical diffusivity to be much greater (order $5 \times 10^{-4} \mathrm{~m}^{2} \mathrm{~s}^{-1}$ ). Other workers (Shimaraev and Granin, 1991; Shimaraev et al. 1994) have employed the heat budget method obtaining vertical diffusivities (averaged over several months) again of order $10 \times 10^{-4}$ $\mathrm{m}^{2} \mathrm{~s}^{-1}$.

In this study, we estimate the vertical diffusivity without tracers. Thus, we are free of limitations of tracer methods such as assumptions about the initial distribution of tracer and about which processes are being measured. The technique is based on a balance of turbulent kinetic energy (TKE). We collected temperature microstructure profiles that resolve the turbulent structure of temperature and thereby provide information on small-scale mixing. Analysis of the profiles led to estimates of TKE dissipation and subsequently vertical diffusivity. Since it is known, that boundary mixing is an important source of TKE in deep natural waters (Wüest et al. 1996; Goudsmit et al. 1997), we also estimate the dissipation of TKE in the bottom boundary layer of the south basin. Finally the microstructure and current turbulence data are integrated in an energy budget in order to address spatial and temporal issues of energetics and mixing.

The presented data were collected during five cruises, organized by the Baikal International Center of Ecological Research (BICER) during December 1995, June and July 1996, December 1996, July 1997 and December 1997. The analyzed data consists of: wind data sampled at the shore of the south basin (WS in Fig. 1); 8 CTD profiles (taken monthly from RV Vereshchagin during 1996 and 1997); 25 temperature microstructure profiles from the three basins to a depth of $600 \mathrm{~m}$ (collected from RV Titov in June/July 1996); a two year record of twice daily $\sim 25$ min current bursts (at $1 / 3 \mathrm{~Hz}$ ) with a 2D acoustic Doppler velocity (ADV) meter at 4 or $105 \mathrm{~m}$ above bottom in 1390-m deep water in the south basin (S in Fig. 1); and a two year record of average current every 20 min measured with the same ADV.

\section{Temperature stratification and diapycnal mixing}

Annual cycle of the temperature structure in the south basin-The seasonal evolution of the vertical temperature structure in Lake Baikal during 1996-1997 is depicted in Fig. 2a,b. Temperature contours in the top $300 \mathrm{~m}$ (Fig. 2a) indicate the summer and winter stratification of the surface and the nearly uniform temperature during transitional periods in early summer and early winter. Significant changes to the temperature stratification (inverse in winter) are confined to the top $150 \mathrm{~m}$. Selected CTD-temperature profiles from the south basin (below 300 m; Fig. 2b) demonstrate the permanent character of the deep-water stratification though the 1997 data suggests near-bottom cold water intrusions.

Although below $250 \mathrm{~m}$ the water column is permanently stratified, stability, $\mathrm{N}^{2}=\mathrm{g}\left[\alpha \cdot \partial \theta / \partial \mathrm{z}-\gamma_{\rho}\left(\partial \mathrm{k}_{20} / \partial \mathrm{z}\right)\right]\left[\mathrm{s}^{-2}\right]$, is extremely low compared with other natural waters. Here, $\partial \theta$ / $\partial \mathrm{z}$ is the potential temperature gradient, $\partial \mathrm{k}_{20} / \partial \mathrm{z}$ is the gradient of the electric conductivity, $\gamma_{\rho}$ : the ratio of the density increase per electric conductivity increase, $g$ is the acceler- 

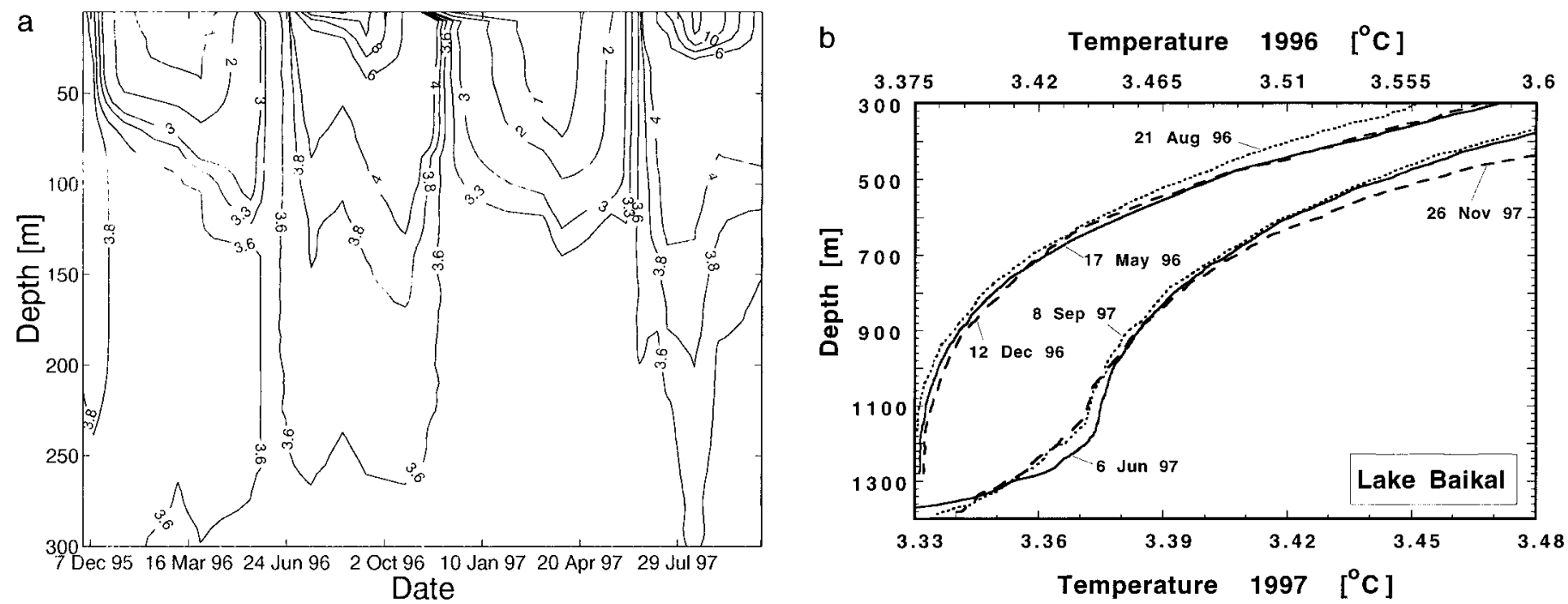

Fig. 2. (a) CTD-based temperature contours in the upper $300 \mathrm{~m}$ in the south basin from December 1995 until October 1997. (b) Temperature profiles (below $300 \mathrm{~m}$ ) from the South basin. The profiles are an average from 8 CTD profiles taken on the specified day. The upper and lower scales apply to the 1996 and 1997 profiles, respectively.

ation due to gravity. The weakness of the stratification $\left(\mathrm{N}^{2}\right.$ $\sim 2 \times 10^{-8} \mathrm{~s}^{-2}$ ) is due to (1) the extremely small $\partial \theta / \partial \mathrm{z},(2)$ the small coefficient of thermal expansion $\alpha$ at temperatures close to the temperature of maximum density $\left(\mathrm{T}_{\mathrm{md}} \sim\right.$ $3.98-0.0021\left[\mathrm{C} \mathrm{m}^{-1}\right] \times$ depth $\left.[\mathrm{m}]\right)$ and (3) the lack of significant salinity gradients (Hohmann et al. 1997). Generally, the water column stability is determined by the vertical temperature gradient. However, near $\mathrm{T}_{\mathrm{md}}$ the temperature-gradient contribution to $\mathrm{N}^{2}$ vanishes $(\alpha \sim 0)$ and stability is determined by the vertical salinity gradient.

Such low stability in the permanently stratified deep water (PSDW) calls for large scales $\left(\epsilon \cdot \mathrm{N}^{-3}\right)^{1 / 2}$ of shear induced eddies. The large depth of the water body, in contrast, gives rise to low dissipation rates $\epsilon$ [W kg-1] and weak mixing. We were therefore curious about the properties of the smallscale turbulence and the corresponding diffusivity in the PSDW. In the next section, a diffusivity estimate based on monthly temperature profiles and a heat budget will be presented. In the following section, a diffusivity estimate based on temperature microstructure data will also be presented.

Vertical diffusivity inferred from monthly temperature profiles-The vertical diffusivity $\mathrm{K}_{\mathrm{z}}\left[\mathrm{m}^{2} \mathrm{~s}^{-1}\right]$ in the stratified deep water of the south basin was estimated by applying the heat budget method (Powell and Jassby 1974) to a set of monthly CTD profiles below $200 \mathrm{~m}$. Each monthly profile was the arithmetic mean of $8 \mathrm{CTD}$ casts and was thus a rough basin average. The heat budget method is based on the assumption that at depth $\mathrm{z}$, the vertical turbulent transport of heat, $\rho \cdot c_{\mathrm{p}} \cdot \mathrm{K}_{\mathrm{z}}(\mathrm{z}) \cdot \mathrm{A}(\mathrm{z}) \cdot \partial \mathrm{T}(\mathrm{z}) / \partial \mathrm{z}$, is equal to the rate of change of heat content below $\mathrm{z}$, given by

$$
\int_{\text {maxdepth }}^{z} \rho c_{p} A\left(z^{\prime}\right) \frac{\partial T\left(z^{\prime}\right)}{\partial t} d z^{\prime}
$$

where $\mathrm{A}\left(\mathrm{z}^{\prime}\right)$ is the cross-sectional lake area at depth $\mathrm{z}^{\prime}$ and $\mathrm{c}_{\mathrm{p}}$ is the specific heat. The diffusivity is then determined by:

$$
\mathrm{K}_{\mathrm{z}}=\int_{\text {maxdepth }}^{\mathrm{z}} \mathrm{A}\left(\mathrm{z}^{\prime}\right) \frac{\partial \mathrm{T}\left(\mathrm{z}^{\prime}, \mathrm{t}\right)}{\partial \mathrm{t}} \mathrm{dz^{ \prime }} \cdot\left[\mathrm{A}(\mathrm{z}) \frac{\partial \mathrm{T}(\mathrm{z})}{\partial \mathrm{z}}\right]^{-1}\left[\mathrm{~m}^{2} \mathrm{~s}^{-1}\right]
$$

Eq. (1) was used to study temperature profiles covering the period from June to December in both 1996 and 1997 (Fig. $2 \mathrm{~b})$. Vertical gradients, $\partial \mathrm{T}(\mathrm{z}) / \partial \mathrm{z}$, as well as temporal changes, $\partial \mathrm{T}\left(\mathrm{z}^{\prime}\right) / \partial \mathrm{t}$, were determined for both seasons based on 6 monthly profiles.

The heat budget method was successfully applied on the 1997 CTD data. For $1997, \mathrm{~K}_{\mathrm{z}}$ was estimated to be about 10 $\pm 5 \times 10^{-4} \mathrm{~m}^{2} \mathrm{~s}^{-1}$ between 200 and $300 \mathrm{~m}$ below the surface and about $3 \pm 3 \times 10^{-4} \mathrm{~m}^{2} \mathrm{~s}^{-1}$ between 300 and $600 \mathrm{~m}$ below the surface (Fig. 3). These estimates were based on the assumption of no heat increase below $900 \mathrm{~m}$. In fact, the CTD data indicated that the temperature was decreasing below $900 \mathrm{~m}$ over this period (probably as a result of cold water intrusions). Since such deep cold water intrusions might diffusively cool the water above, they might lead to an underestimate of $K_{z}$. Confidence intervals shown in the figure are based on the uncertainty in the temporal temperature gradient $\partial \mathrm{T}\left(\mathrm{z}^{\prime}\right) / \partial \mathrm{t}$.

With the 1996 CTD data, reliable $\mathrm{K}_{\mathrm{z}}$ estimates were not possible at any depths. Monthly CTD profiles indicated that the temperature in the PSDW did not increase monotonically as one would expect from pure diffusive processes. Instead, the temperatures varied considerably (positively and negatively) in the sequential CTD profiles (Fig. 2b). The lack of a trend in temperature may be related to the lower wind energy input following ice break-up in 1996 relative to 1997.

The uncertainty and difficulty in $\mathrm{K}_{\mathrm{z}}$ estimation is due to lateral temperature heterogeneity and the subsequent horizontal heat flux. In some cases, uncertainty may be reduced by averaging profiles over several years (Shimaraev and Granin 1991). Alternatively, a much larger number of profiles might be sufficient to account for lateral heterogeneity. 


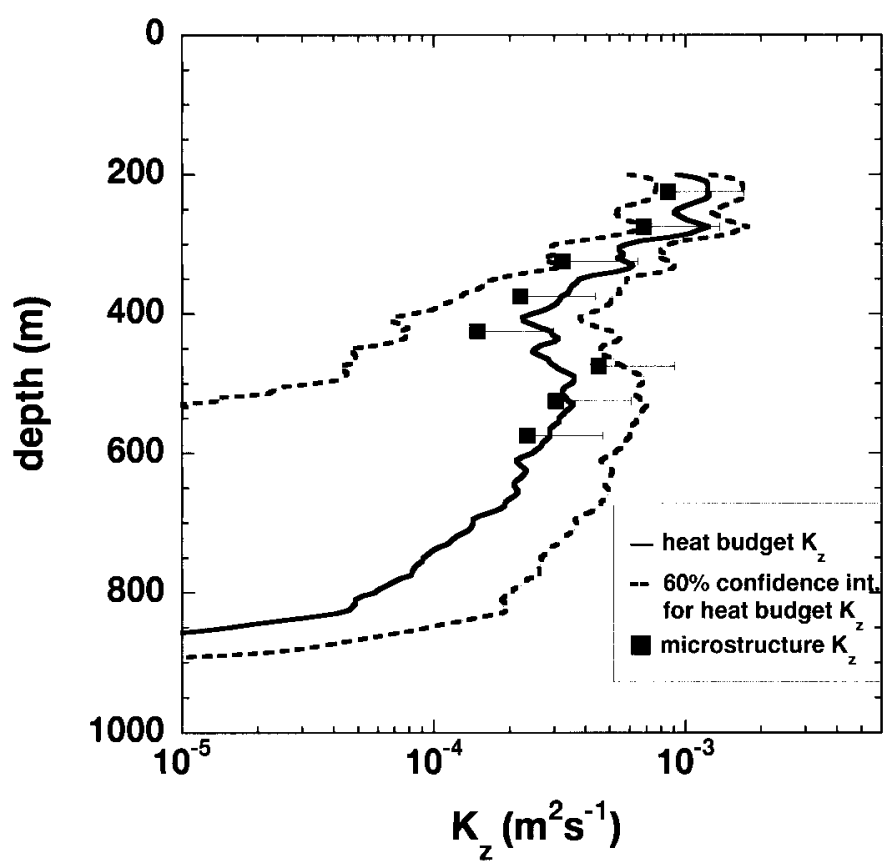

Fig. 3. Vertical diffusivity $\mathrm{K}_{\mathrm{z}}$ as a function of depth in the south basin of Lake Baikal based on CTD (heat budget method) and June and July 1996 temperature microstructure (Osborn-Cox method).

In the latter case, more sophisticated error analysis (Jellison and Melack 1993) might be appropriate.

Given their uncertainty, the heat-budget $\mathrm{K}_{\mathrm{z}}$ values presented here are only an order of magnitude estimate. Nevertheless, the range of $\mathrm{K}_{\mathrm{z}}$ of 10 to $3 \times 10^{-4} \mathrm{~m}^{2} \mathrm{~s}^{-1}$ at depths of 200 to $600 \mathrm{~m}$ is in agreement (1) with the estimate of Frank Peeters (pers. comm.) who estimated a tracer-based, whole-basin $\mathrm{K}_{\mathrm{z}}$ of $5 \times 10^{-4} \mathrm{~m}^{2} \mathrm{~s}^{-1}$ (for depths greater than $400 \mathrm{~m})$ and (2) with the estimate of Shimaraev and Granin (1991) inferring $\mathrm{K}_{\mathrm{z}} \cong 10 \times 10^{-4} \mathrm{~m}^{2} \mathrm{~s}^{-1}$ for the layer at depths of 200 to $800 \mathrm{~m}$, based on the heat budget method averaged over several years. In order to illuminate the discrepancy with the Killworth et al. (1996) estimates and remove any remaining uncertainty, we carried out turbulence (temperature microstructure) measurements and obtained a tracer-independent $\mathrm{K}_{\mathrm{z}}$ estimate.

\section{Diapycnal mixing inferred from temperature microstructure}

Temperature microstructure method-The temperature microstructure method is based on the fact that temperature gradients - at least very small ones-are always present in natural waters. The relationship between temperature fluctuations at the smallest length scales $(\sim \mathrm{mm})$, where temperature differences are smoothened by thermal diffusivity $\kappa_{\mathrm{T}}\left[\mathrm{m}^{2} \mathrm{~s}^{-1}\right]$, and the intensity of turbulent mixing is described by Batchelor's (1959) theory. Under isotropic and stationary conditions, the spectrum of one-dimensional temperature fluctuations follows the form
$\phi_{\mathrm{T}}(\mathrm{x})=\frac{\pi \chi \kappa_{\mathrm{T}}^{1 / 2} \mathrm{q}^{3 / 2} \boldsymbol{\nu}^{3 / 4}}{\epsilon^{3 / 4}}\left(\frac{\mathrm{e}^{-\mathrm{x}^{2}}}{\mathrm{x}}-\sqrt{\pi}(1-\operatorname{erf}(\mathrm{x}))\right)\left[\mathrm{K}^{2}(\mathrm{cpm})^{-1}\right]$

where $\mathrm{x}=2 \pi \mathrm{k}_{\mathrm{z}} \mathrm{K}_{T}^{1 / 2} \boldsymbol{\nu}^{1 / 4} q^{1 / 2} \epsilon^{-1 / 4}$ is the non-dimensional wave number, $\mathrm{k}_{\mathrm{z}}[\mathrm{cpm}]$ is the one-dimensional wave number, $v$ is the kinematic viscosity of water $\left(1\right.$ to $\left.1.5 \times 10^{-6} \mathrm{~m}^{2} \mathrm{~s}^{-1}\right)$, and $\mathrm{q}$ is the experimentally determined turbulence parameter set to $\mathrm{q}=3.4$ (Dillon and Caldwell 1980; Oakey 1982). Rates of dissipation of TKE, $\epsilon$ [W kg-1], and of temperature variance, $\chi\left[\mathrm{K}^{2} \mathrm{~s}^{-1}\right]$, were determined by fitting the spectra of 2-m long measured temperature profile segments to the model spectrum of Eq. (2). As given below in Eqs. (3) and (4), diapycnal diffusivity has been determined from those two basic turbulence quantities, $\epsilon$ and $\chi$, for temperature microstructure profiles collected in all three basins of Lake Baikal (Fig. 1) in June and July 1996. Note that the microstructure method does not refer to a coordinate system and the diffusivity inferred is, strictly speaking, a diffusivity in the direction of the temperature gradient (i.e., diapycnal). However, since temperature gradients are typically vertical, diapycnal is practically vertical.

Temperature and its fluctuations were collected at $96 \mathrm{~Hz}$ from a FP07 fast-response thermistor using an adapted SBE9 CTD as $\mu$ T-profiler (SeaBird, Bellevue, USA; Gloor et al. 1995). The probe was allowed to fall freely at a speed of $w_{P}$ $\sim 0.1 \mathrm{~m} \mathrm{~s}^{-1}$ to $\sim 600 \mathrm{~m}$, limited by pressure constraints of the CTD pressure case. Data were transmitted to the computer on board via a thin and slightly-negatively buoyant electrical cable. To reduce quantization noise of the temperature fluctuations $\mathrm{T}^{\prime}$ at small scales, pre-emphasis (Mudge and Lueck 1994) was applied by linearly enhancing the $T^{\prime}$ signal (as a function of frequency) before 16 bit A/D conversion (Gloor et al. 1995; Kocsis et al. 1999). Response time correction and de-emphasis was applied to the calculated spectra before fitting Eq. (2) to $\phi_{\mathrm{T}}\left(\mathrm{k}_{\mathrm{z}}\right)$. We assumed a speed-dependent response time of the FP07 sensor of $\tau_{\text {Resp }} \sim$ $\left(\mathrm{w}_{\mathrm{p}} / \mathrm{m} \mathrm{s}^{-1}\right)^{-0.32 .7} \times 10^{-3} \mathrm{~s}\left(=15 \times 10^{-3} \mathrm{~s}\right.$ for $\mathrm{w}_{\mathrm{p}}=0.1 \mathrm{~m}$ $\mathrm{s}^{-1}$ ), according to Gregg and Meagher (1980). Temperature spectra, calculated from the $2 \mathrm{~m}$ long vertical segments, which did not follow Batchelor's form (less than $10 \%$ of the spectra) were rejected and not analyzed further. With this arrangement, dissipation $\epsilon$ (when between $10^{-12}$ and $7 \times$ $10^{-6} \mathrm{~W} \mathrm{~kg}^{-1}$ ) and $\chi$ (when between $10^{-12}$ and $10^{-6} \mathrm{~K}^{2} \mathrm{~s}^{-1}$ ) can be resolved from within a factor of 2 (detailed analysis of noise level in Kocsis et al. 1999). In Lake Baikal values varied actually from $8.0 \times 10^{-12}$ to $4.3 \times 10^{-7} \mathrm{~W} \mathrm{~kg}^{-1}$ for $\epsilon$ and from $8 \times 10^{-13}$ to $3 \times 10^{-6} \mathrm{~K}^{2} \mathrm{~s}^{-1}$ for $\chi$.

From $\epsilon$ and $\chi$ diapycnal diffusivity (K) was calculated by both the Osborn-Cox and dissipation methods. The OsbornCox model (Osborn and Cox 1972) estimates diapycnal diffusivity based on an assumed balance between the generation of temperature fluctuations $\left\langle\mathrm{T}^{\prime 2}\right\rangle$ by turbulent vertical overturns in a mean temperature gradient $\mathrm{dT} / \mathrm{dz}$ and its dissipation $\chi$ due to molecular diffusion. Neglecting all other $\mathrm{T}^{\prime}$-variance producing processes and assuming isotropy for scales smaller than the overturns leads to

$$
\mathrm{K}_{\chi}=0.5 \cdot \chi \cdot(\mathrm{dT} / \mathrm{dz})^{-2}\left[\mathrm{~m}^{2} \mathrm{~s}^{-1}\right]
$$


The dissipation method assumes a stationary balance between the buoyancy flux $\left(\mathrm{K} \cdot \mathrm{N}^{2}\right)$, the production of potential energy by turbulent mixing against the stratified water column of stability $\mathrm{N}^{2}$, and dissipation $\epsilon$ of TKE. We further assumed that a constant fraction of the dissipated TKE, expressed by the mixing efficiency $\gamma_{\text {mix }}$, is transformed to buoyancy flux. With these assumptions, the vertical diffusivity is calculated as

$$
\mathrm{K}_{\epsilon}=\frac{\gamma_{\mathrm{mix}} \epsilon}{\mathrm{N}^{2}}\left[\mathrm{~m}^{2} \mathrm{~s}^{-1}\right]
$$

where $\gamma_{\text {mix }}$ is expected among $\gamma_{\text {mix }} \sim 0.12$ (Peters and Gregg 1988) and 0.2 (Osborn 1980).

Since the Lake Baikal $\gamma_{\text {mix }}$ was uncertain, we proceeded by first calculating $\mathrm{K}_{\bar{x}}$-the Osborn-Cox $\mathrm{K}_{z}$. Then, the $\gamma_{\text {mix }}$ was obtained by using $K_{\chi}$ in Eq. 4 (i.e., $\gamma_{\text {mix }}=\mathrm{K}_{\chi} \mathrm{N}^{2} / \epsilon$ ). Substituting for $\mathrm{K}_{x}$ using Eq. 3, we have:

$$
\gamma_{\text {mix }}=\frac{\chi \mathrm{N}^{2}}{2 \epsilon\left(\frac{\mathrm{dT}(\mathrm{z})}{\mathrm{dz}}\right)^{2}}[-]
$$

For both methods the quantities involved $\left(\epsilon, \mathrm{N}^{2}, \chi\right.$ and $\mathrm{dT} /$ $\mathrm{dz}$ ) were averaged over 50-m long vertical segments and subsequently $\gamma_{\text {mix }}, K_{\epsilon}$ and $K_{x}$ were calculated with the same vertical resolution (Fig. 4). The 50-m bins were chosen in order to obtain (1) reliable background stability, since the vertical extent of overturning eddies (Ozmidov scale $\left.\left(\epsilon \cdot \mathrm{N}^{-3}\right)^{1 / 2}\right)$ can reach tens of meters and (2) statistically robust averages, since $\epsilon$ - and even more so $\chi$ - show broad intermittence (Yamazaki and Lueck 1990). Hence, given that each 50-m bin contained $252-\mathrm{m}$ estimates and given 4 to 10 profiles per station, the averages of $\chi$ and $\epsilon$, as shown in Fig. 4, consist of 100 to 250 individual 2-m estimates. We assume, that dissipation and consequently also diffusivity is correct within a factor of 2, as comparisons with shear microstructure (Oakey 1982; Kocsis et al. 1999) as well as with tracers (Wüest et al. 1996), have demonstrated. Error associated with the temperature gradient $(\mathrm{dT} / \mathrm{dz})$ calculation was minimal given the high resolution of the SBE temperature sensor $(0.15 \mathrm{mK})$.

Microstructure observations-Between 28 June 1996 and 10 July 1996 a joint cruise of the Limnological Institute of Irkutsk and EAWAG was undertaken in order to conduct temperature microstructure profiling in all three basins of Lake Baikal (Fig. 1). In two legs, first heading northward then southward, at least 10 profiles were collected in every basin (52 profiles in total) from R.V. Titov down to a maximum depth of $600 \mathrm{~m}$. The south and middle basin stations during the northward leg were designated S1 and M1, respectively. The same stations during the southward leg were designated S2 and M2. The temperature sensor was damaged during deployment in the south basin at the end of the southward leg of the cruise (S2). Microstructure data from that portion is, therefore, not reported here though the data was of sufficient quality for temperature plotting (Fig. 4a). The data of the 25 deepest profiles (Table 1) are included in this analysis. Fig. 4 summarizes the microstructure observations at the four stations in the south (S1), middle (M1, M2) and north basin $(\mathrm{N})$, with respect to temperature (a), stability (b), dissipation $\chi$ of temperature variance (c), dissipation $\epsilon$ of TKE (d), mixing efficiency $\gamma_{\text {mix }}$ (e) and diffusivities $\mathrm{K}_{\chi}$ and $\mathrm{K}_{\epsilon}(\mathrm{f})$.

a) Temperature (Fig. 4a): During the period of microstructure measurements, the water column below $\sim 200-250 \mathrm{~m}$ was stably stratified in respect to temperature in all three basins. Above $200 \mathrm{~m}$, the different phases of the after icebreak up temperature development are evident. Whereas in the south basin, where ice break-up occurred about 2 months previously, temperature was always above $\mathrm{T}_{\mathrm{md}}$ (thin straight lines in Fig. 4a), temperature stratification in the north basin was still inverse (ice break-up $\sim 20 \mathrm{~d}$ delayed relative to south basin). In the middle basin, the surface layer was nearly homogeneous (indicating free convection).

b) Stability of the water column (Fig. 4b): The different phases of the seasonal temperature development were also evident in the stability of the water column. The south basin had high surface and near-bottom stratification with a nearconstant middle depth stratification of $2 \times 10^{-8} \mathrm{~s}^{-2}$. The middle basin had low surface stratification due to the nearconstant temperature, a relatively high middle depth stratification of $4 \times 10^{-8} \mathrm{~s}^{-2}$, and a near-bottom stratification peak. The north basin had high surface stability due to the inverse temperature stratification but exhibited a distinct minima at about 250-m depth at the location of $\mathrm{T}_{\mathrm{md}}$.

c) Dissipation of temperature variance, $\chi$, (Fig. 4c): In all three basins $\chi$ showed an approximately exponential decrease as a function of depth (decreasing by $1 / \mathrm{e}$ every 50 $\mathrm{m})$ from $\sim 10^{-7} \mathrm{~K}^{2} \mathrm{~s}^{-1}$ at the surface to $\sim 10^{-10} \mathrm{~K}^{2} \mathrm{~s}^{-1}$ below $400 \mathrm{~m}$. Between M1(June 29-30) and M2 (July 6) $\chi$ between 200 and $400 \mathrm{~m}$ decreased by a factor of 3 and between 400 and $600 \mathrm{~m}$ by one order of magnitude-significantly more than the bootstrap standard deviations. In the north basin $\chi$ increased at a depth of about $200 \mathrm{~m}$, where stratification (Fig. 4b) was very weak.

d) Dissipation of TKE, $\epsilon$, (Fig. 4d): With the exception of the top 50 to $100 \mathrm{~m}$ of the south basin where a sharp decrease in $\epsilon$ was observed, $\epsilon$ decreased exponentially in the top $400 \mathrm{~m}$ and then leveled off between $10^{-10}$ and $10^{-11} \mathrm{~W}$ $\mathrm{kg}^{-1}$ below $400 \mathrm{~m}$. The level of dissipation in the middle basin was greater in the earlier northward cruise probably due to horizontal variability.

e) Mixing efficiency (Fig. 4e): Neglecting a few outlying data points (some resulting from uncertainty in the temperature gradient due to very weak stratification and one resulting from an extremely low dissipation estimate), the mixing efficiency averaged $0.16 \pm 0.11$. The median considering all the data from the three basins was 0.17 . It seemed that $\gamma_{\text {mix }}$ is smaller in the surface layer $(0.12 \pm 0.11)$ than in the permanently stratified water below 300-m depth $(0.22 \pm 0.07)$, but due to the large scatter this increase may not be significant. 

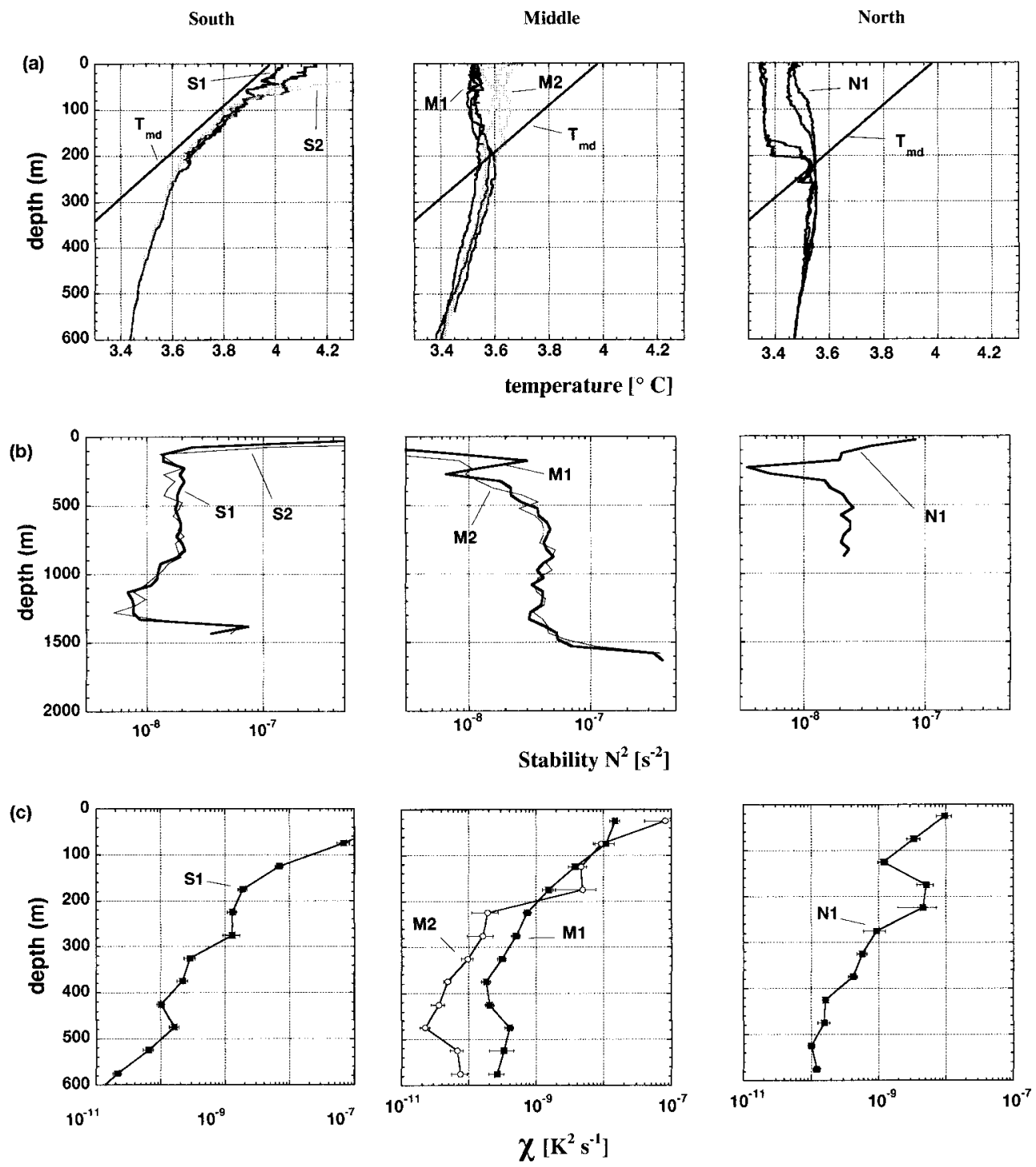

Fig. 4. Microstructure temperature (a), stability (b) and estimates of $\chi(c), \epsilon(d)$, mixing efficiency (e), and $K_{z}$ (f) based on microstructure profiles (Table 1) collected in the south (left panels), middle, and north basin (right panels). The error bars indicate the standard deviation calculated with the bootstrap method. Data is presented from both the northerly stretch of the cruise (S1, M1, and N1) and the southerly return stretch (S2 and M2).

f) Diapycnal diffusivity (Fig. 4f): The diapycnal diffusivity $\mathrm{K}_{\chi}$ and $\mathrm{K}_{\epsilon}$ (Fig. 4f) were calculated using the OsbornCox (Eq. 3) and dissipation method (Eq. 4), respectively. The calculations were based on the station-averaged quantities presented in Figs. $4 \mathrm{a}-\mathrm{d}$ and assuming $\gamma_{\text {mix }}=0.16$. As one would expect from the structure of dissipation and stability, diapycnal diffusivity tended to be largest in the surface layer (with values exceeding $10^{-2} \mathrm{~m}^{2} \mathrm{~s}^{-1}$ ) and decreased to order $5 \times 10^{-4} \mathrm{~m}^{2} \mathrm{~s}^{-1}$ at $300 \mathrm{~m}$. Below $300 \mathrm{~m}$ vertical diffusivity tended to level off at $(9 \pm 2) \times 10^{-4} \mathrm{~m}^{2} \mathrm{~s}^{-1}$ for the Cox method and at $(6 \pm 2) \times 10^{-4} \mathrm{~m}^{2} \mathrm{~s}^{-1}$ for the dissipation method considering all three basins. The uncertainty of the estimates reflects variability in $\chi$. As with the dissipation estimates, the vertical diffusivity estimates for M1 are at least twice as big as those for M2 probably due to horizontal variability.

From the microstructure measurements we conclude that in the south basin, the diapycnal diffusivity estimated from the microstructure analysis was in rough agreement with the heat-budget derived $\mathrm{K}_{\mathrm{z}}$ (Fig. 3). Both methods indicated relatively high $\mathrm{K}_{\mathrm{z}}$ between $200-300 \mathrm{~m}\left(6\right.$ to $\left.20 \times 10^{-4} \mathrm{~m}^{2} \mathrm{~s}^{-1}\right)$ with reduced levels ( 1 to $5 \times 10^{-4} \mathrm{~m}^{2} \mathrm{~s}^{-1}$ ) between 300 and $600 \mathrm{~m}$. In addition, the microstructure diffusivity estimates are consistent with a deep water (below $400 \mathrm{~m}$ ) estimate based on tracers $\left(5 \times 10^{-4} \mathrm{~m}^{2} \mathrm{~s}^{-1}\right.$, Frank Peeters pers. comm.). However, it is significantly ( 2 to 3 orders of magnitude) more than that estimated by Killworth et al. (1996). Considering all three basins, the permanently stratified water 

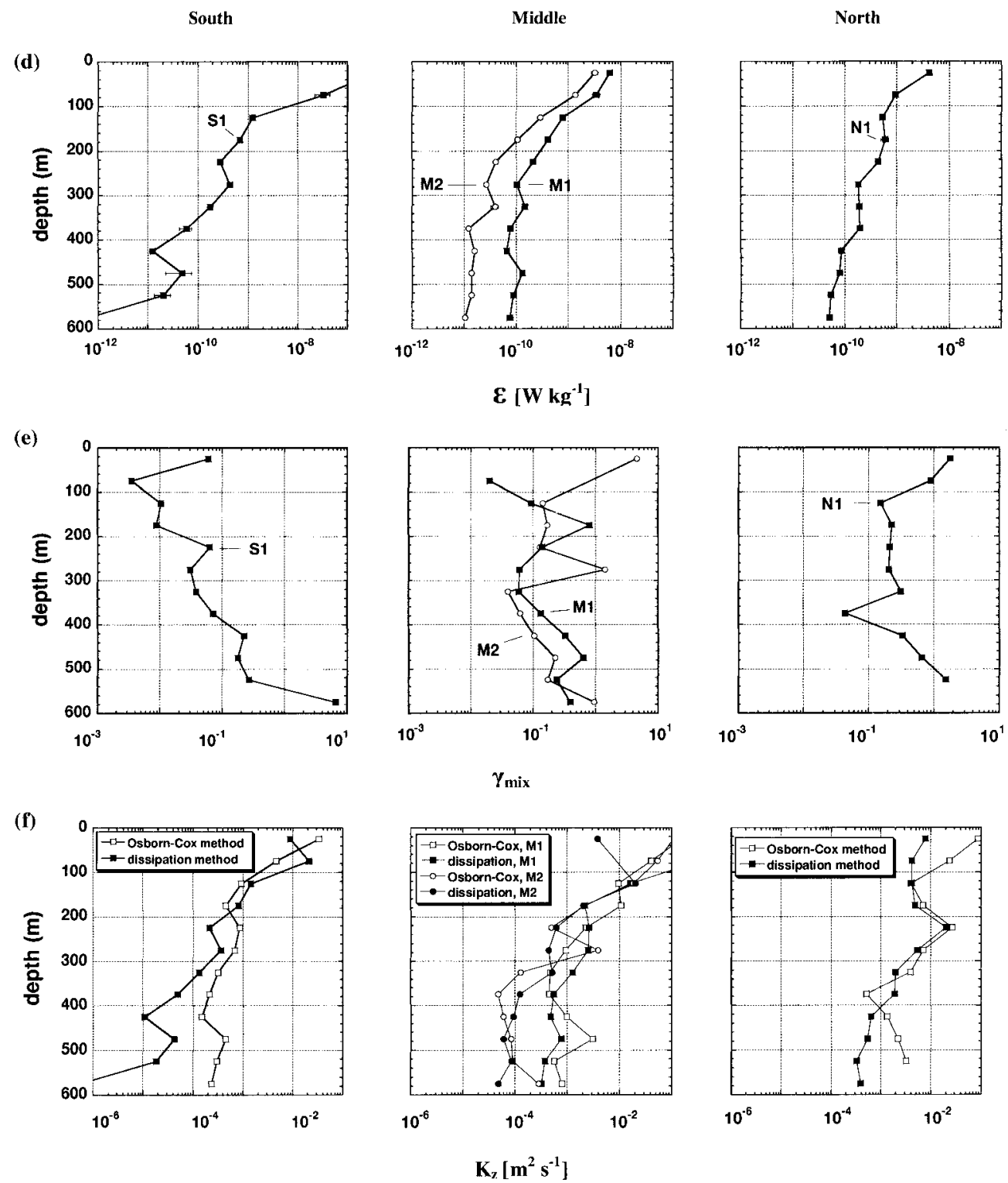

Fig. 4. Continued.

column between 300 and $600 \mathrm{~m}$ had an average diapycnal diffusivity of about $9 \times 10^{-4} \mathrm{~m}^{2} \mathrm{~s}^{-1}$. Again, this is consistent with the tracer based estimate of Frank Peeters (pers. comm.) who estimated diffusivity to be 5,6 , and $2 \times 10^{-4} \mathrm{~m}^{2} \mathrm{~s}^{-1}$ for the south, middle and north basins.

Table 1. Number and position of the microstructure profiles collected in June-July 1996.

\begin{tabular}{lcc}
\hline \hline \multicolumn{1}{c}{ Period } & Number of profiles & Location (Fig. 1) \\
\hline 26-28 Jun 96 & 5 & $\mathrm{~S}$ \\
29 Jun-1 Jul 96 & 4 & $\mathrm{M}$ \\
2-5 Jul 96 & 6 & $\mathrm{~N}$ \\
6 Jul 96 & 10 & $\mathrm{M}$ \\
8-9 Jul 96 & $10^{*}$ & $\mathrm{~S}$ \\
Total & 25 & \\
\hline
\end{tabular}

* Data were analyzed but not reported because of suspected sensor damage.
Since Osborn (1980) proposed $\gamma_{\text {mix }}=0.2$ as an upper limit for the open ocean, many estimates based on microstructure measurements (Moum 1990; Oakey 1982; Yamazaki and Osborn 1993; Oakey 1988; Gregg et al. 1986; Peters and Gregg 1988; Gargett and Moum 1995; Moum 1996) and laboratory measurements (Rohr and Van Atta 1987) have been published. Often a range of values was found, with the conclusion that $\gamma_{\text {mix }}$ depends on the physical processes of the flow such as the degree of stratification and the source and intensity of the turbulence. In this context it is interesting that the $\gamma_{\text {mix }}$ obtained here (0.16) from the weakly stratified Lake Baikal is consistent with findings in more stratified natural waters.

Bottom current dynamics and energetics

Bottom currents observations-Near-bottom currents were measured for nearly two years (Table 2 ) from a moor- 
Table 2. Vertical level of moored instruments at position $S$ (local depth $=1,390 \mathrm{~m}$ ).

\begin{tabular}{|c|c|c|c|}
\hline Deployment period & $\begin{array}{c}\text { Current meter } \\
\text { (height above bottom) } \\
\mathrm{h}(\mathrm{m})\end{array}$ & $\begin{array}{c}\text { Bottom thermistor string } \\
\text { (height above bottom) } \\
\mathrm{h}_{1} \ldots \mathrm{h}_{11}(\mathrm{~m})\end{array}$ & $\begin{array}{c}\text { Surface thermistor string } \\
\text { (depth) } \\
\mathrm{z}_{1} \ldots \mathrm{z}_{11}(\mathrm{~m})\end{array}$ \\
\hline 8 Dec 95-26 Jun 96* & 105 & 4. . .104 & None \\
\hline 28 Jun $96-11$ Dec 96 & 4 & $13 \ldots 113$ & 44. . 144 \\
\hline 12 Dec 96-8 Jul 97 & 4 & $13 \ldots 113$ & 44. . 144 \\
\hline 9 Jul 97-26 Nov 97 & 105 & 4. . .104 & 44. . .144 \\
\hline
\end{tabular}

* Current meter failed on 4 May 1996 (data available only from 8 December 1995 to 3 May 1996).

ing located close to the deepest site in the south basin (at ' $\mathrm{S}$ ' in Fig. 1) at a depth of $1,390 \mathrm{~m}$ (inset in Fig. 1). Current data were collected every $20 \mathrm{~min}$ at either $4 \mathrm{~m}$ (indicated by $\mathrm{U}_{4 \mathrm{~m}}$ ) or $105 \mathrm{~m}$ (indicated by $\mathrm{U}_{105 \mathrm{~m}}$ ) above bottom (Table 2) by a $2 \mathrm{D}$ ADV (acoustic Doppler velocity meter SACM3, EG\&G Marine Instruments, Burlington, MA-USA).

The observation period comprised three periods of open water (448 d without ice cover; Table 3) and two periods with ice cover (206 d; Table 3; ice cover indicated by thick horizontal line in Fig. 5). Over all, there is no dramatic seasonal structure in the deep water currents (Table 3; Fig. 5b), which averaged about $3 \times 10^{-2} \mathrm{~m} \mathrm{~s}^{-1}$. However, the current dynamics in the south basin indicated some damping during the periods of ice cover. Analysis of kinetic energy $(E=0.5$ $\mathrm{U}^{2}$, Fig. 5c), indicated decay time constants of the deep water currents under ice was 40 and $36 \mathrm{~d}$ for the two winters (Table 3). By the end of the period of ice cover, the measured speed (Fig. 5) fell nearly to zero $\left(<5 \times 10^{-3} \mathrm{~m} \mathrm{~s}^{-1}\right)$, confirming the zero-point laboratory calibration.

After ice break-up, it took months for the deep-water currents in the south basin to recover to the level of open water conditions. The recovery of the current energy was faster in 1997 as a result of the stronger wind energy $\left(\mathrm{P}_{10}\right)$ in spring that year (Fig. 5a). Here, $\mathrm{P}_{10}\left(=\rho_{\text {air }} \mathrm{C}_{10} \mathrm{~W}_{10}^{3}\right)$ is the vertical wind energy flux at $10 \mathrm{~m}$ above water where $\rho_{\text {air }}$ is the air density, $\mathrm{C}_{10}$ is the drag coefficient, and $\mathrm{W}_{10}$ is the wind speed at $10 \mathrm{~m}$ above water. In the 2 months following ice breakup the average wind energy flux was 0.087 and $0.141 \mathrm{~W}$ $\mathrm{m}^{-2}$ in 1996 and 1997, respectively. Assuming a typical water velocity of $0.03 \mathrm{~m} \mathrm{~s}^{-1}$, a $1000-\mathrm{m}$ water depth, and a $0.1 \%$ efficiency of energy transfer from wind to deep water (see discussion below), one obtains time scales for recovery of deep water kinetic energy of $\sim 2$ months $(70 \mathrm{~d}$ ) and $\sim 1.5$ months (40 d) in 1996 and 1997, respectively.

Beside the seasonal dynamics (ice-open water), the deepwater currents show fluctuations for at least two shorter time scales. The most prominent variations occur at a frequency of $1.6 \mathrm{~d}^{-1}$ (Fig. 6). The fact that this peak in the current spectrum corresponds nearly perfectly to the Coriolis frequency $f \sim 1.58 \mathrm{~d}^{-1}\left(\sim 1.15 \times 10^{-4} \mathrm{~s}^{-1}\right)$ at the local latitude of $\phi=52^{\circ} \mathrm{N}\left(f=2 \cdot \Omega \sin (\phi) ; \Omega=0.73 \times 10^{-4} \mathrm{~s}^{-1}\right)$ indicates strong inertial features. The intensity of the inertial deepwater currents is apparently significantly stronger for open water conditions-when the inertial range contributes by far the most to the kinetic energy (Fig. 6a) - than under icecover, when inertial currents become completely eradicated (Fig. 6b). This observation suggests that the currents in the lowest layers of this very deep lake draw the energy mainly from wind, which pumps energy at the inertial scale $(\mathrm{km}-$ range) into the lake - a feature which evidently can exist for open water only.

For frequencies above $\mathrm{f}$, the contribution to the current

Table 3. Summary of bottom boundary energetics during 1996 and 1997.

\begin{tabular}{|c|c|c|c|c|c|c|c|c|c|c|}
\hline \multirow[b]{2}{*}{ Time } & \multirow{2}{*}{$\begin{array}{l}\text { Length } \\
\text { (d) }\end{array}$} & \multirow{2}{*}{$\begin{array}{c}\text { Ice/ } \\
\text { open } \\
\text { water }\end{array}$} & \multirow{2}{*}{$\begin{array}{l}\text { Height } \\
\text { above } \\
\text { bottom } \\
(\mathrm{m})\end{array}$} & \multirow{2}{*}{$\begin{array}{c}\text { Bottom } \\
\text { current } \\
\left\langle\mathrm{u}_{\mathrm{h}}{ }^{3}\right\rangle \\
\left(\left[\mathrm{m} \mathrm{s}^{-1}\right]^{3}\right)\end{array}$} & \multicolumn{3}{|c|}{ Dissipation } & & & \multirow{2}{*}{$\begin{array}{c}\text { Wind } \\
-\quad \mathrm{W}_{10^{3}} \\
\left(\mathrm{~m}^{3} \mathrm{~s}^{-3}\right) \\
\end{array}$} \\
\hline & & & & & $\begin{array}{c}\left\langle\epsilon_{\mathrm{LOW}}\right\rangle^{*} \\
\left(10^{-10} \mathrm{~W}\right. \\
\left.\mathrm{kg}^{-1}\right)\end{array}$ & $\begin{array}{c}\left\langle\epsilon_{\mathrm{ED}}\right\rangle \dagger \\
\left(10^{-10} \mathrm{~W} \mathrm{~kg}^{-1}\right) \\
\end{array}$ & $\begin{array}{c}\mathrm{P}_{\text {bot }} \ddagger \\
\left(\mu \mathrm{W} \mathrm{m}^{-2}\right)\end{array}$ & $\tau_{\mathrm{E}} \S$ & $1.5 \tau_{\text {Diss }} \|$ & \\
\hline 10 Dec 95-17 Jan 96 & 38 & Open & 105 & $10.210^{-5}$ & 0.77 & $0.58 \pm 0.3$ & $102(173)$ & - & - & 185 \\
\hline 18 Jan 96-3 Mar 96 & 106 & Ice & 105 & $5.110^{-5}$ & 0.38 & $0.28 \pm 0.1$ & $51(87)$ & 40 & 39 & 106 \\
\hline 30 Jun 96-16 Jan 97 & 200 & Open & 4 & $5.510^{-5}$ & 24.1 & $30.1 \pm 5$ & $122(85)$ & - & - & 117 \\
\hline 12 Jul 97-26 Nov 97 & 138 & Open & 105 & $7.710^{-5}$ & 0.58 & $1.2 \pm 0.4$ & $77(131)$ & & & 86 \\
\hline Mean & 206 & Ice & & $5.310^{-5} \pi$ & & & $53963)$ & $38 \pm 2$ & $42 \pm 3$ & 144 \\
\hline Values & 448 & Open & & $9.510^{-54}$ & & & $95(89)$ & & & 111 \\
\hline
\end{tabular}

* $\epsilon_{\mathrm{LOw}}$ is determined from $\left\langle\mathrm{u}_{\mathrm{h}}{ }^{3}\right\rangle$ by using $\epsilon_{\mathrm{LOw}}=\mathrm{u}^{* 3} /(\kappa \mathrm{h})$, where $\mathrm{\kappa}=0.41$ is the von Karman constant, $\mathrm{u}^{*}=\mathrm{C}_{\mathrm{h}}{ }^{1 / 2} \mathrm{u}_{\mathrm{h}}$, and $\mathrm{h}=$ height above lake bottom;

$\mathrm{C}_{1 \mathrm{~m}}=2.310^{-3}, \mathrm{C}_{\mathrm{h}}$ is calculated according to $\mathrm{C}_{\mathrm{h}}=\mathrm{C}_{\mathrm{lm}} \ln ^{2}\left(1 \mathrm{~m} / \mathrm{z}_{0}\right) / \mathrm{ln}^{2}\left(\mathrm{~h} / \mathrm{z}_{0}\right)$ with $\mathrm{z}_{0}=0.1 \mathrm{~mm}$.

$\dagger \epsilon_{\mathrm{ID}}$ is determined from the current fluctuations $\mathrm{u}_{\mathrm{h}}$ at height $\mathrm{h}$ above bottom by using the inertial dissipation method.

$\ddagger \mathrm{P}_{\text {bot }}$ is determined by using $\mathrm{P}_{\text {bot }}=\rho \mathrm{C}_{105 \mathrm{~m}}\left\langle\mathrm{u}_{105 \mathrm{~m}}\right\rangle$; $; \mathrm{C}_{105 \mathrm{~m}}$ and $\mathrm{u}_{105 \mathrm{~m}}$ corrected assuming Law and the Wall (LOW). The parenthetic data indicate how the estimate would vary if the logarithmic layer extended only to $4 \mathrm{~m}$ above bottom.

$\S \tau_{\mathrm{E}}$ determined from the decay of kinetic energy $\left(\left\langle\mathrm{u}_{\mathrm{h}}{ }^{2}\right\rangle / 2\right)$ under ice.

$\| \tau_{\text {Diss }}$ determined the decay of near-bottom dissipation under ice.

II The reported velocities are those estimated at $105 \mathrm{~m}$ above bottom based on the mean $\mathrm{P}_{\text {bot }}$ using the relation in the footnote above. 
(a)

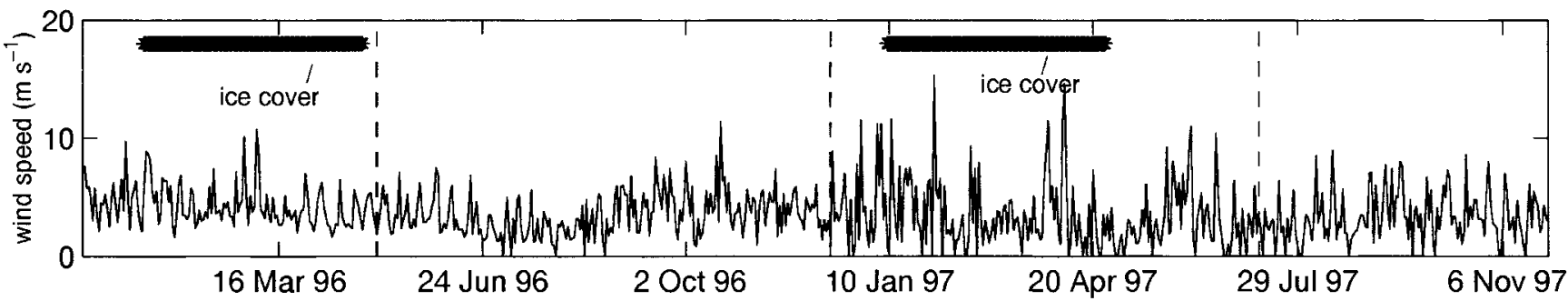

(b)

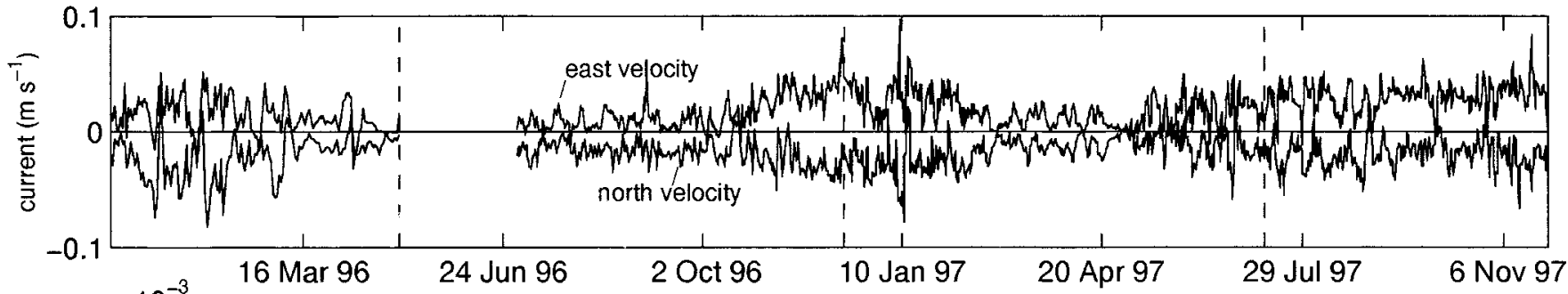

(c)

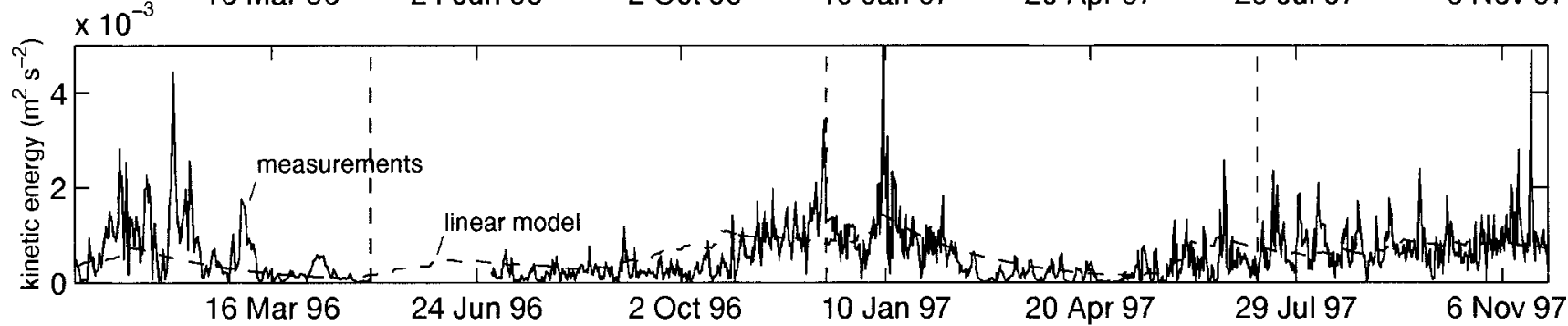

(d)

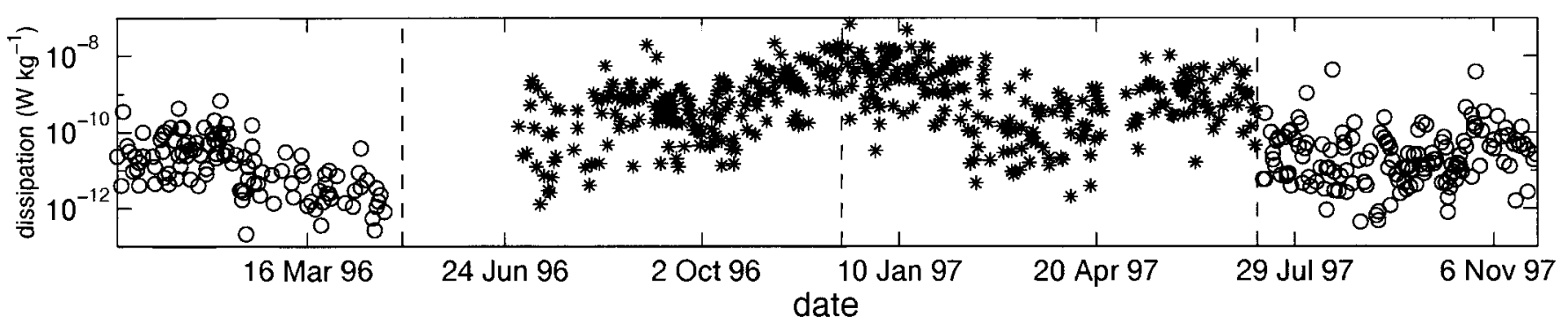

Fig. 5. (a) Daily wind speed throughout the time of the four velocity meter deployments. The two thick horizontal lines indicate the time of ice cover. The dashed vertical lines demarcate the various deployment periods given in Table 2. (b) The north (lower line) and the east component (upper line) of velocity during the four deployments. The position of the velocity meter was $105 \mathrm{~m}$ above bottom in the first and fourth deployment and $4 \mathrm{~m}$ above bottom in the second and third (Table 2). (c) Measured and modeled kinetic energy during the four deployments. Measurements were based on near-bottom ADV data. (d) Dissipation rate during the deployments determined from the level of the inertial subrange of the velocity spectra.

variance (Fig. 6a) is most probably due to eddies progressively decaying from inertial scales toward the dissipation range. Fluctuations of the smaller ( $\mathrm{dm}$ to $\mathrm{m}$ ) and shorter (s to min) eddies will be analyzed in the next subsection.

The second noteworthy contribution seen in the energy conserving plot (Fig. 6a,b) stems from eddies with length and time scales of several $\mathrm{km}$ and several days, respectively. This is probably the result of synoptic forcing wind since a similar peak is seen in the wind speed spectra. Compared with smaller and more stratified basins, the current spectra contains hardly any basin-scale seiching probably a consequence of the long seiche time scale (order months, Wetzel 1983).

Dissipation estimation from inertial subrange velocity spectra-Between the energy containing range (here $\sim \mathrm{U} / \mathrm{f}$ ) and the dissipative range $\left(10^{-2} \mathrm{~m}\right)$, the turbulent eddies can decay freely and develop a so-called inertial subrange. If the stratification allows the eddies to become isotropic, the velocity power spectra $\phi(\mathrm{k})$ depends only on the wavenumber $\mathrm{k}[\mathrm{rad}$ $\mathrm{m}^{-1}$ ] and the rate of dissipation $\epsilon$ of TKE by

$$
\phi(\mathrm{k})=\alpha \epsilon^{2 / 3} \mathrm{k}^{-5 / 3}\left[\mathrm{~m}^{2} \mathrm{~s}^{-2}\left(\mathrm{rad} \mathrm{m}^{-1}\right)^{-1}\right]
$$

where $\alpha=1.56$ (Wyngaard and Cote 1971) is the threedimensional Kolmogorov constant. Since the ADV measured horizontal (2D) current fluctuations at a fixed Eulerian point, we were able to determine only the two one-dimensional spectra: $\phi_{11}$ (spectra of the longitudinal current) and $\phi_{22}$ (spectra of the horizontal transverse current). Assuming again isotropy, those spectra follow 

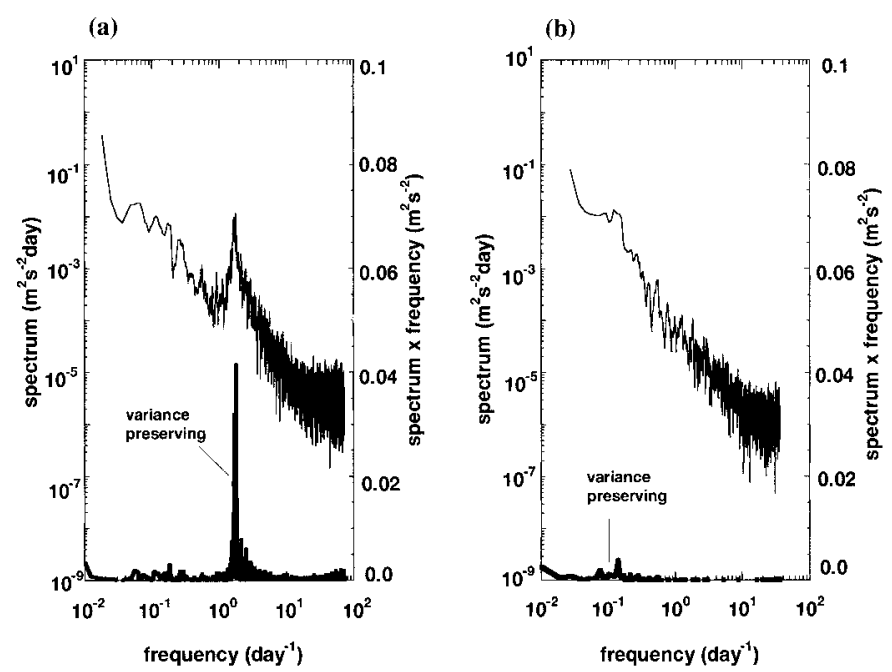

Fig. 6. Velocity spectrum (light, upper line) and the variancepreserving spectrum $\times$ frequency (heavy line) during (a) an open water period (30 June 1996-11 December 1996) and (b) under ice (17 January 1997-27 April 1997). For open water conditions, where the currents are higher, the spectrum peaks at $1.6 \mathrm{~d}^{-1}$ (=local inertial frequency). The peak is not visible during the calm ice-covered periods (b).

$$
\begin{aligned}
& \left.\phi_{11}=\alpha_{1} \epsilon^{2 / 3} \mathrm{k}_{1}^{-5 / 3}\left[\mathrm{~m}^{2} \mathrm{~s}^{-2}(\operatorname{rad~m})^{-1}\right)^{-1}\right] \\
& \phi_{22}=\alpha_{2} \epsilon^{2 / 3} \mathrm{k}_{1}^{-5 / 3}\left[\mathrm{~m}^{2} \mathrm{~s}^{-2}(\operatorname{rad~m})^{-1}\right]
\end{aligned}
$$

with $\alpha_{1}=(18 / 55) \cdot \alpha, \alpha_{2}=(4 / 3) \cdot(18 / 55) \cdot \alpha$, and $k_{1}$ is the onedimensional wavenumber.

Velocity bursts of 500 samples collected at $1 / 3 \mathrm{~Hz}$ were obtained 2 times per day. For each burst, the average velocity direction was calculated. The original data was then projected on the longitudinal and transverse direction obtaining two velocity time series. From the longitudinal and transverse velocity time series, frequency domain velocity spectra $\phi_{11}$ and $\phi_{22}$ were calculated and then transformed into the wave number domain by invoking Taylor's frozen turbulence assumption (wave number $=2 \pi$ velocity $^{-1}$ frequency). Following Terray et al. (1996), $\phi_{22} \mathrm{k}_{1}{ }^{5 / 3}$ and $\phi_{11} \mathrm{k}_{1}{ }^{5 / 3}$ were calculated producing 'flat spectra' (see Eqs. 7a,b) from which dissipation $\left(\epsilon=\operatorname{mean}\left(\left(\phi_{22} \mathrm{k}_{1}{ }^{5 / 3} / \alpha_{2}\right)^{3 / 2}\right)\right.$ or $\epsilon=\operatorname{mean}\left(\left(\phi_{11} \mathrm{k}_{1}{ }^{5 / 3} /\right.\right.$ $\left.\alpha_{1}\right)^{3 / 2}$ ) and its error (e.g., standard deviation) could be readily calculated. Due to its reduced error, we proceeded solely with the transverse velocity-based estimates.

Dissipation in the bottom boundary layer of the south basin-The dissipation estimates ranged from $\sim 10^{-12}$ to several $10^{-8} \mathrm{~W} \mathrm{~kg}^{-1}$ (Fig. 5d, Table 3). The dissipation dynamics are clearly related to the cycle of open water and ice-cover. Whereas after the ice break-up, dissipation gradually increases as the deep water currents strengthen, dissipation decays approximately exponentially as a function of time under ice-cover with a time constant of one month $\left(\tau_{\text {Diss }}\right.$ $=26$ and $30 \mathrm{~d}$ in the 1996 and 1997 ice coverage periods, respectively). Given that dissipation scales with the cube of velocity and kinetic energy $\mathrm{E}=0.5 \cdot \mathrm{U}^{2}$ with velocity squared (Eq. 8, below), $\tau_{\mathrm{E}}=1.5 \cdot \tau_{\text {Diss }}$. The corresponding time scales

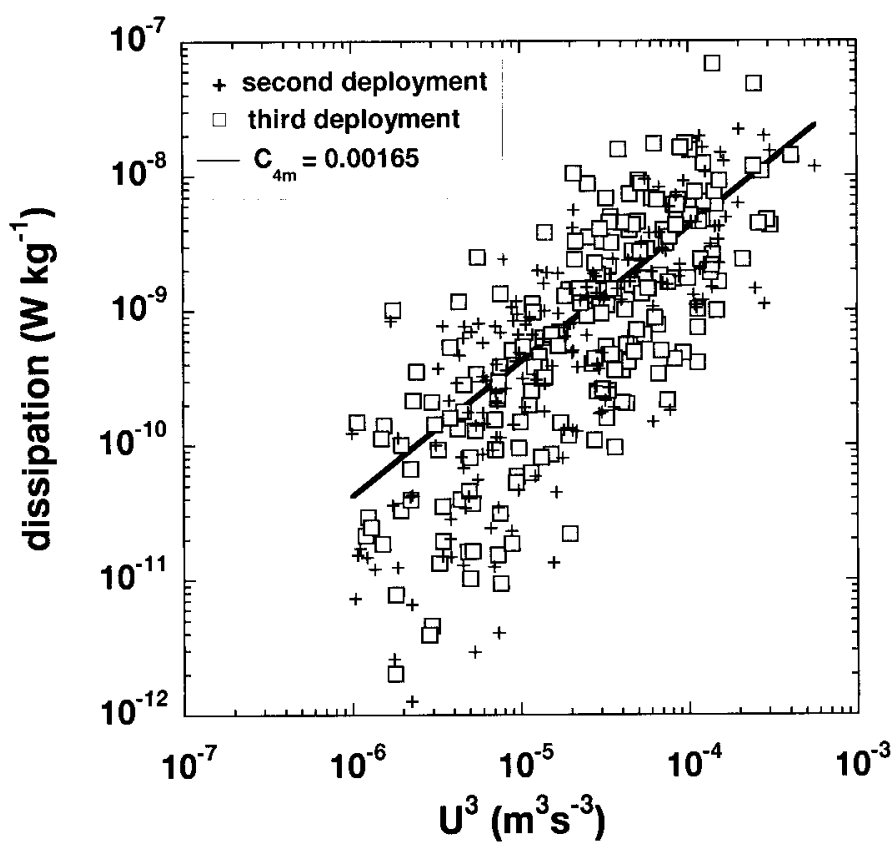

Fig. 7. Dissipation versus the cube of velocity $\left(\mathrm{U}_{4 \mathrm{~m}}^{3}\right)(4 \mathrm{~m}$ above bottom, at S; Fig. 1) during the second and third deployments. A near-linear relationship is evident suggesting that these velocity measurements at $4 \mathrm{~m}$ above bottom are in the BBL.

of the decay of the kinetic energy $\left(\tau_{\mathrm{E}}\right)$ are, therefore, $\tau_{\mathrm{E}} \sim$ 39 and $45 \mathrm{~d}$ for the 1996 and 1997 ice coverage periods, respectively. These estimates are in good agreement with the $\tau_{\mathrm{E}}$ estimates obtained directly from $\mathrm{E}$. We proceed using $\tau_{\mathrm{E}}$ $=40 \mathrm{~d}$ on the basis of the kinetic energy and dissipation data (Table 3).

The level of the observed dissipation depended strongly on the distance $\mathrm{h}$ of the ADV from the lake bottom. During the second and third deployments ( $\mathrm{h} \sim 4 \mathrm{~m}$ ), dissipation (stars in Fig. 5d) was more than an order of magnitude greater, compared with the first and fourth deployments $(\mathrm{h} \sim 105$ $\mathrm{m}$; circles in Fig. 5d). In addition, dissipation estimates for $\mathrm{h} \sim 4 \mathrm{~m}$ were found to be linearly related to the cube $\mathrm{U}_{4 \mathrm{~m}}^{3}$ of the velocity (Fig. 7), whereas such a relation did not apply for $\mathrm{h} \sim 105 \mathrm{~m}$. This strongly suggests that the ADV was well within the turbulent bottom boundary layer (BBL) for $\mathrm{h} \sim 4 \mathrm{~m}$ but above BBL for $\mathrm{h} \sim 105 \mathrm{~m}$. Assuming, the 'Law Of the Wall' (LOW) to be applicable-which is typically the case for smooth flow over the fine sediments in lakes and oceans - the dissipation $\epsilon$ as a function of $U$ scales as:

$$
\begin{aligned}
\epsilon(\mathrm{h}) & =\left(\tau_{\mathrm{o}} / \rho\right) \cdot(\partial \mathrm{U} / \partial \mathrm{h})=\mathrm{u}_{*}^{3} / \kappa \mathrm{h}=\mathrm{C}_{4 \mathrm{~m}}^{1.5} \cdot \mathrm{U}_{4 \mathrm{~m}}^{3} / \kappa \mathrm{h} \\
& =\mathrm{C}_{1 \mathrm{~m}}^{1.5} \cdot \mathrm{U}_{1 \mathrm{~m}}^{3} / \kappa \mathrm{h}\left[\mathrm{W} \mathrm{kg}^{-1}\right]
\end{aligned}
$$

where $\tau_{\mathrm{o}}$ is the bottom shear stress, $\mathrm{u}_{*}=\left(\tau_{\mathrm{o}} / \rho\right)^{1 / 2}$ is the friction velocity, $\kappa=0.41$ is the von Karman constant, and $\mathrm{C}_{4 \mathrm{~m}}$, $\mathrm{C}_{1 \mathrm{~m}}$ and $\mathrm{U}_{4 \mathrm{~m}}, \mathrm{U}_{1 \mathrm{~m}}$ are the drag coefficients and currents for $\mathrm{h}=4$ and $1 \mathrm{~m}$ above bottom, respectively. Linear regression of Eq. (8) to the data in Fig. 7 leads to $C_{4 m} \sim 1.5$ and 1.8 $\times 10^{-3}$ for the second and third deployments, respectively. 
Using LOW $\mathrm{C}_{4 \mathrm{~m}}$ can be transformed to $\mathrm{C}_{1 \mathrm{~m}}$ by $\mathrm{C}_{1 \mathrm{~m}}=$ $\mathrm{C}_{4 \mathrm{~m}}\left(\ln ^{2}\left(4 / \mathrm{z}_{\mathrm{o}}\right)\right) /\left(\ln ^{2}\left(1 / \mathrm{z}_{\mathrm{o}}\right)\right)$. Assuming that the roughness parameter $\mathrm{z}_{\mathrm{o}}$ associated with smooth turbulent flow was $\mathrm{z}_{\mathrm{o}} \sim$ $0.1 \mathrm{~mm}\left(=0.1 \nu / \mathrm{u}_{*}\right), \mathrm{C}_{1 \mathrm{~m}}$ estimates of 2.0 and $2.7 \times 10^{-3}$ were made for the second and third deployments, respectively. These values are close to others found in smooth flow regimes of the ocean and other lakes (e.g., $\mathrm{C}_{1 \mathrm{~m}}=1.5 \times$ $10^{-3}$, Elliott 1984).

Near-bottom kinetic energy modeling-The measured near-bottom current kinetic energy $\mathrm{E}$ (throughout the four deployments) was compared with a linear model which assumes a wind energy input $\left(\mathrm{E}_{\text {in }}=\mathrm{f}_{\text {eff }} \mathrm{P}_{10} \mathrm{AM}^{-1}\right)$ and decay of water kinetic energy $\left(E / \tau_{\mathrm{E}}\right)$, i.e.,

$$
\mathrm{dE} / \mathrm{dt}=\mathrm{f}_{\text {eff }} \mathrm{P}_{10} \mathrm{AM}^{-1}-\mathrm{E} \tau_{\mathrm{E}}^{-1}\left[\mathrm{~W} \mathrm{~kg} \mathrm{~kg}^{-1} \mathrm{or}^{2} \mathrm{~s}^{-3}\right]
$$

where $\mathrm{f}_{\text {eff }}$ is the fraction of the wind energy flux $\left(\mathrm{P}_{10}\right)$ entering the lake, $\mathrm{A}\left(=5.9 \times 10^{9} \mathrm{~m}^{2}\right)$ is the surface area of the PSDW of the south basin, and $\mathrm{M}\left(=4.6 \times 10^{15} \mathrm{~kg}\right)$ is the mass of the PSDW. The model was optimized when $\mathrm{f}_{\text {eff }}=$ $7.0 \times 10^{-4}$ and $\tau=50 \mathrm{~d}$ (dashed line in Fig. 5c). In addition, a non-linear model, which (more realistically) assumed a kinetic energy loss scaling with $\mathrm{E}^{1.5}\left(\approx \mathrm{U}^{3}\right)$ was considered (i.e., $\mathrm{dE} / \mathrm{dt}=\mathrm{f}_{\text {eff }} \mathrm{P}_{10} \mathrm{AM}^{-1}-\mathrm{CE}^{1.5}$ ) where $\mathrm{C}$ is a constant. This model was optimized with $\mathrm{f}_{\text {eff }}=9.3 \times 10^{-4}$ and $\mathrm{C}=$ $9 \times 10^{-6} \mathrm{~m}^{-1}$. From the constant $\mathrm{C}$, a time constant of 53 $\mathrm{d}$ was obtained $\left(\tau=\mathrm{C}^{-1} \mathrm{E}_{\text {ave }}^{-0.5}\right.$ where $\mathrm{E}_{\text {ave }}$ is the average kinetic energy $\left.=5.9 \times 10^{-4} \mathrm{~m}^{2} \mathrm{~s}^{-2}\right)$. However, the mean square error of the linear model was somewhat less $(5.3 \times$ $10^{-4} \mathrm{~m}^{2} \mathrm{~s}^{-2}$ as opposed to $5.5 \times 10^{-4} \mathrm{~m}^{2} \mathrm{~s}^{-2}$ ).

Considering the whole data set, the time constant for decay of kinetic energy was slightly longer than that observed under the ice ( $\sim 40 \mathrm{~d}$; Table 3$)$. The reason for this may be that the dissipation for open water conditions is less efficient. During the open water period from 30 June 1996 to 16 January 1997, $\tau_{\mathrm{E}}$ (from the linear model) was $60 \mathrm{~d}$ (Table 3). However, the kinetic energy decay time constants from the linear model are uncertain relative to those from analysis of the decay of kinetic energy under ice. This is because of the imprecision of parts of the model such as the wind energy input efficiency constant which may well vary temporally due to changes in the air-water temperature differential and due to changes in surface stratification. Due to our greater confidence in the under-ice derived decay constant, we employ this constant in the remainder of the paper and assume that it is applicable throughout the year.

\section{Turbulent kinetic energy balance in the south basin}

Energy input by wind-As shown in Fig. 6 the energy for mixing in the deep water layers of Lake Baikal stems from wind energy entering the lake at the inertial scale. As this scale $(\mathrm{km})$ is much shorter than the lake dimensions (hundreds of $\mathrm{km}$ ), the energy input occurs locally and without much time delay (as compared with basin scale forcing in small/medium lakes). This enables TKE to be balanced locally and episodically.

We use the turbulent vertical wind energy flux $10 \mathrm{~m}$ above lake water $\left(\mathrm{P}_{10}\right)$ as a reference for the TKE balance, being
Table 4. Summary of measured wind speed and wind-induced vertical energy flux.

\begin{tabular}{|c|c|c|c|c|c|}
\hline Summary & Unit & South & $\begin{array}{l}\text { Mid- } \\
\text { dle }\end{array}$ & North & $\begin{array}{l}\text { Aver- } \\
\text { age }\end{array}$ \\
\hline \multicolumn{6}{|l|}{ Long term* } \\
\hline $\begin{array}{l}\mathrm{W}_{2} \\
\mathrm{P}_{10} \dagger\end{array}$ & $\begin{array}{l}\mathrm{m} \mathrm{s}^{-1} \\
\mathrm{~mW} \mathrm{~m}^{-2}\end{array}$ & $\begin{array}{c}4.0 \\
142\end{array}$ & $\begin{array}{c}4.2 \\
165\end{array}$ & $\begin{array}{l}3.0 \\
60\end{array}$ & $\begin{array}{r}3.7 \\
122\end{array}$ \\
\hline \multicolumn{6}{|l|}{ 1996-1997 } \\
\hline $\begin{array}{l}\mathrm{W}_{2} \text { average } \\
\mathrm{P}_{10} \text { open water } \\
\mathrm{P}_{10} \text { annual average } \\
\mathrm{P}_{10} \text { microstructure cast } \\
\mathrm{P}_{10} \text { microstructure cast } \\
\mathrm{P}_{10} \text { annual average, to- } \\
\text { tal }\end{array}$ & 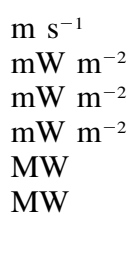 & $\begin{array}{c}3.7 \\
113 \ddagger \\
75 \ddagger \S \\
35 \ddagger \| \\
207 \| \\
444 \|\end{array}$ & & & \\
\hline 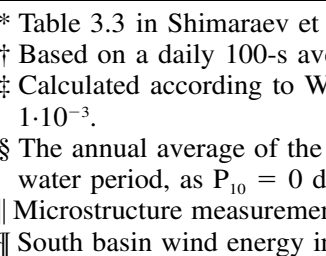 & $\begin{array}{l}\text { 1. (1994). } \\
\text { rage. } \\
=1.22 \cdot \mathrm{V} \\
\text { energy flux } \\
\text { aring ice co } \\
t \text { from } 26 \mathrm{~J} \\
\text { put rate ass }\end{array}$ & $\begin{array}{l}\text { and } \mathrm{P} \\
{ }_{0} \text { is } \mathrm{sr} \\
\mathrm{r} \text {. } \\
\text { e to } 9 \\
\text { ning a }\end{array}$ & $\begin{array}{l}=\mathrm{C}_{\mathrm{D}} \cdot \rho_{\mathrm{a}} \\
\text { ler than } \\
\text { ly } 1996 \\
\text { rface }\end{array}$ & $\begin{array}{l}\cdot \mathrm{W}_{10}{ }^{3} \mathrm{wi} \\
\text { during }\end{array}$ & $\begin{array}{l}\mathrm{C}_{\mathrm{D}}= \\
\text { e open } \\
19 \mathrm{~km}^{2}\end{array}$ \\
\hline
\end{tabular}

aware that only a few $\%$ of $\mathrm{P}_{10}$ enter the water body. During $1996 / 1997$ the mean wind speed $\mathrm{W}_{2}$ (measured $2 \mathrm{~m}$ above water) in the south basin $\left(3.7 \mathrm{~m} \mathrm{~s}^{-1}\right)$ was at the same level as the long term average in the south basin $\left(4.0 \mathrm{~m} \mathrm{~s}^{-1}\right)$, as well as the long term average in all three basins $\left(3.7 \mathrm{~m} \mathrm{~s}^{-1}\right)$ (Shimaraev et al. 1994; Table 4). There is no significant difference in wind intensity between the period of ice cover $\left(3.8 \mathrm{~m} \mathrm{~s}^{-1}\right)$, which lasted for $103 \pm 3 \mathrm{~d}$ from mid-January through April and the period of open water $\left(3.6 \mathrm{~m} \mathrm{~s}^{-1}\right)(\mathrm{Ta}-$ bles 3-5). Since there is no energy input during ice-cover $\left(103 / 365\right.$ of the time), the annual average energy flux $P_{10}$ in the south basin for the two years of observations was 75 $\mathrm{mW} \mathrm{m}{ }^{-2}$ (compared with $113 \mathrm{~mW} \mathrm{~m}^{-2}$ without ice cover).

At the time of the microstructure data collection in June and July $96, \mathrm{P}_{10} \sim 35 \mathrm{~mW} \mathrm{~m}^{-2}$ was only half of the annual average (Table 4). As will be shown below, the level of turbulence during microstructure measurements was also about half of the 2 year average.

Dissipation in the surface layer-According to the microstructure data from the three basins, TKE dissipation was concentrated in the top $\sim 50 \mathrm{~m}$ (average of $2.2 \times 10^{-8} \mathrm{~W}$ $\mathrm{kg}^{-1}$ ). In the top $150 \mathrm{~m}$, dissipation decreased approximately exponentially with depth decreasing by $1 / \mathrm{e}$ every $22 \mathrm{~m}$. During the period of the microstructure measurement, the dissipation in the lake was between 1.2 and $1.5 \mathrm{~mW} \mathrm{~m}^{-2}$ (depending on the vertical integration), i.e., $\sim 3-4 \%$ of $\mathrm{P}_{10}$. This fraction seems to be typical for stratified waters (Holloway 1980) and is consistent with that found in other turbulence studies (Imberger 1985), given the inhomogeneous wind field and the uncertain residence time of the kinetic energy in the lake.

Dissipation in the interior of the stratified deep waterBelow 150-m depth, microstructure data indicated that dis- 
Table 5. Vertical distribution of measured dissipation of TKE based on microstructure data (June-July 1996*) and based on near-bottom velocity data.

\begin{tabular}{|c|c|c|c|c|c|c|}
\hline $\begin{array}{c}\text { Dissipation, } \\
\text { June-July } 1996\end{array}$ & & $\begin{array}{c}\text { South } \\
{\left[\mathrm{mW} \mathrm{m}^{-2}\right]}\end{array}$ & $\begin{array}{c}\text { Middle } \\
{\left[\mathrm{mW} \mathrm{m}^{-2}\right]}\end{array}$ & $\begin{array}{c}\text { North } \\
{\left[\mathrm{mW} \mathrm{m}^{-2}\right]}\end{array}$ & $\begin{array}{c}\text { Average } \\
{\left[\mathrm{mW} \mathrm{m}^{-2}\right]}\end{array}$ & $\begin{array}{c}\text { Total } \dagger \\
{[\mathrm{kW}]}\end{array}$ \\
\hline 0 - to $250-\mathrm{m}$ depth & $\left\langle\mathrm{P}_{\text {top }}\right\rangle$ & 10.0 & 0.40 & 0.33 & 3.6 & 23,000 \\
\hline $250-$ to $600-\mathrm{m}$ depth & $\left\langle\mathrm{P}_{\text {hyp }}\right\rangle$ & 0.023 & 0.020 & 0.041 & 0.028 & 151 \\
\hline BBL to bottom $\S$ & $\left\langle\mathrm{P}_{\text {bot }}\right\rangle$ & & & & 0.032 & 189 \\
\hline $250 \mathrm{~m}$ to $\mathrm{BBL}$ & $\left\langle\mathrm{P}_{\text {strat }}\right\rangle$ & & & & & 207 \\
\hline $250 \mathrm{~m}$ to bottom $\S$ & $\left\langle\mathrm{P}_{\text {strat }}+\mathrm{P}_{\text {bot }}\right\rangle$ & & & & & 396 \\
\hline
\end{tabular}

* Microstructure measurement from 26 June to 9 July 1996.

$\dagger$ Quantities shown are based on the average quantities from the preceding column as well as bathymetric data from the south basin.

$\$$ Calculated as described in the section on the TKE balance. BBL $=$ bottom boundary layer.

$\S \mathrm{P}_{\text {bot }}$ is determined by using $\mathrm{P}_{\text {bot }}=\rho \mathrm{C}_{105 \mathrm{~m}}\left\langle\mathrm{u}_{105 \mathrm{~m}}{ }^{3}\right\rangle ; \mathrm{C}_{105 \mathrm{~m}}$ and $\mathrm{u}_{105 \mathrm{~m}}$ were calculated assuming Law of the Wall (LOW). Total dissipation calculation assumes a bottom area of $5,919 \mathrm{~km}^{2}$ (portion of basin bottom with $z>250 \mathrm{~m}$ ).

sipation decreased exponentially with depth, decreasing by $1 / \mathrm{e}$ every $180 \mathrm{~m}$, and reached a level of $4.2 \times 10^{-11} \mathrm{~W} \mathrm{~kg}^{-1}$ (Fig. 4d) in 600-m depth. Between 600-m depth and the BBL, we lack information on dissipation. It is noteworthy that the annual average of the ADV dissipation estimates determined at $105 \mathrm{~m}$ above bottom was $8.2 \times 10^{-11} \mathrm{~W} \mathrm{~kg}^{-1}$ (Table 3)-about twice as much as the microstructure $\epsilon$ in $600 \mathrm{~m}$. Also, we estimate that dissipation at $\mathrm{h}=105 \mathrm{~m}$ during the microstructure measurements was about $2.510^{-11}$ $\mathrm{W} \mathrm{kg}{ }^{-1}$ based on current data (at $\mathrm{h}=4 \mathrm{~m}, 28-30$ June 1996) and LOW, (see Table 3, first footnote). Unfortunately, our data does not allow us to say conclusively whether the dissipation data at $105 \mathrm{~m}$ above bottom reflects interior conditions or BBL conditions. The fact that there was no apparent relationship between $\mathrm{U}_{105 \mathrm{~m}}^{3}$ and dissipation would suggest that $\mathrm{h}=105 \mathrm{~m}$ was above the BBL. However, LOW estimates of dissipation from velocity (Table 3 ) indicate that the observed dissipation levels could result from BBL turbulence.

For the purposes of estimating water column dissipation, we proceed on the basis of a conservative (low) assumption and a non-conservative (high) assumption. The conservative assumption is that the 105-m ADV data reflected the BBL and not the interior. Below $600 \mathrm{~m}$ dissipation continued to decrease exponentially with the same $(180 \mathrm{~m})$ length scale. This assumption leads to an integrated dissipation between $600 \mathrm{~m}$ and $1290 \mathrm{~m}$ of $0.007 \mathrm{~mW} \mathrm{~m}^{-2}$. The non-conservative assumption is that (during the microstructure measurements) the dissipation remained constant at an average $3.3 \times 10^{-11}$ $\mathrm{W} \mathrm{kg}{ }^{-1}$ until the BBL (the average of $4.2 \times 10^{-11} \mathrm{~W} \mathrm{~kg}^{-1}$ at $600 \mathrm{~m}$ and $2.5 \times 10^{-11} \mathrm{~W} \mathrm{~kg}^{-1}$ estimated at $105 \mathrm{~m}$ above bottom). This assumption implies an integrated dissipation between $600 \mathrm{~m}$ and $1290 \mathrm{~m}$ of $0.023 \mathrm{~mW} \mathrm{~m}^{-2}$. For simplicity, we take the average integrated dissipation $(0.015 \mathrm{~mW}$ $\mathrm{m}^{-2}$ ) and proceed. Considering the south basin bathymetry and surface area, the total dissipation in the PSDW (not including the bottom boundary layer) is $207 \mathrm{~kW}$ (Table 5, i.e., $0.1 \%$ of $\mathrm{P}_{10}$, Table 4$)$. This fraction $(0.1 \%)$ is comparable to that found in other stratified natural waters including the ocean (Gregg and Sanford 1988) and other lakes (e.g., Farmer and Carmack 1981). A vertical integration of dissipation data in the interior deep water $\left(\mathrm{P}_{\text {strat }}\right)$, (i.e., forgoing volume averaging), yields about $0.04 \mathrm{~mW} \mathrm{~m}^{-2}$.

Dissipation in the bottom layer near maximum depthThe integrated TKE dissipation within the BBL, $\mathrm{P}_{\text {bot }}$ (Table 3 ), was estimated by assuming a 105-m thick logarithmic bottom layer and using a calculated drag coefficient $\left(\mathrm{C}_{105 \mathrm{~m}}\right)$ of 0.001 (Table 3). Considering $\mathrm{P}_{\mathrm{bot}}$ from the various time periods (Table 3 ), we obtained a 2 -year weighted average $\mathrm{P}_{\text {bot }}$ of $0.082 \mathrm{~mW} \mathrm{~m}^{-2}$. The open-water and under-ice $\left\langle\mathrm{P}_{\text {bot }}\right\rangle$ were $0.095 \mathrm{~mW} \mathrm{~m}^{-2}$ and $0.053 \mathrm{~mW} \mathrm{~m}^{-2}$, respectively (Table 3). Again, we see that bottom friction consumes about $\sim 0.1 \%$ of $\mathrm{P}_{10}$. During microstructure measurements $\mathrm{P}_{\text {bot }}$ was only $0.032 \mathrm{~mW} \mathrm{~m}^{-2}$; yet another indication that in June/ July 1996 turbulence was about one half of the 2 year average. Note that the dissipation between $250 \mathrm{~m}$ and the BBL $\left(<\mathrm{P}_{\text {strat }}>\right)$ was about $10 \%$ greater than $<\mathrm{P}_{\text {bot }}>$ during the time of microstructure measurements (Table 5).

Temporal variation of energetics in PSDW-Having studied the spatial distribution of energy dissipation in the PSDW, we turned to the issue of temporal variability. Since, excepting the microstructure measurement period, we lack dissipation data between $250 \mathrm{~m}$ and the $\mathrm{BBL}$, the interior dissipation (between 250 and the BBL, $\left\langle\mathrm{P}_{\text {strat }}\right\rangle$ ) was estimated on the basis of the bottom dissipation velocity using the relationship observed during the microstructure measurement period $\left.\left(<\mathrm{P}_{\text {strat }}\right\rangle=1.1<\mathrm{P}_{\text {bot }}>\right)$.

We estimated the kinetic energy balance for the 1996 and 1997 study period, for periods of ice cover, for open water, and for the period of microstructure measurements (Table 6). The energy dissipation of the PSDW $\left(\mathrm{E}_{\mathrm{M}} / \tau_{\mathrm{E}}\right.$, where $\mathrm{E}_{\mathrm{M}}=$ EM) was estimated for each time period on the basis of the 2 years of ADV current data (and the derived kinetic energy) and using the time scale for kinetic energy decay under ice $\left(\tau_{\mathrm{E}}=40 \mathrm{~d}\right.$, Table 3$)$. In general, these PSDW estimates were in agreement with separate estimates of internal dissipation $\left(\mathrm{P}_{\text {strat }}\right)$ and BBL dissipation $\left(\mathrm{P}_{\text {bot }}\right)$ (from Table 3). That is, PSDW dissipation $\sim \mathrm{P}_{\text {strat }}+\mathrm{P}_{\text {bot }}$.

As discussed previously, the period of microstructure measurements saw energy levels that were one-third to one- 
Table 6. Turbulent kinetic energy balance in the permanently stratified deep water (PSDW, below $250 \mathrm{~m}$ ) of the south basin.

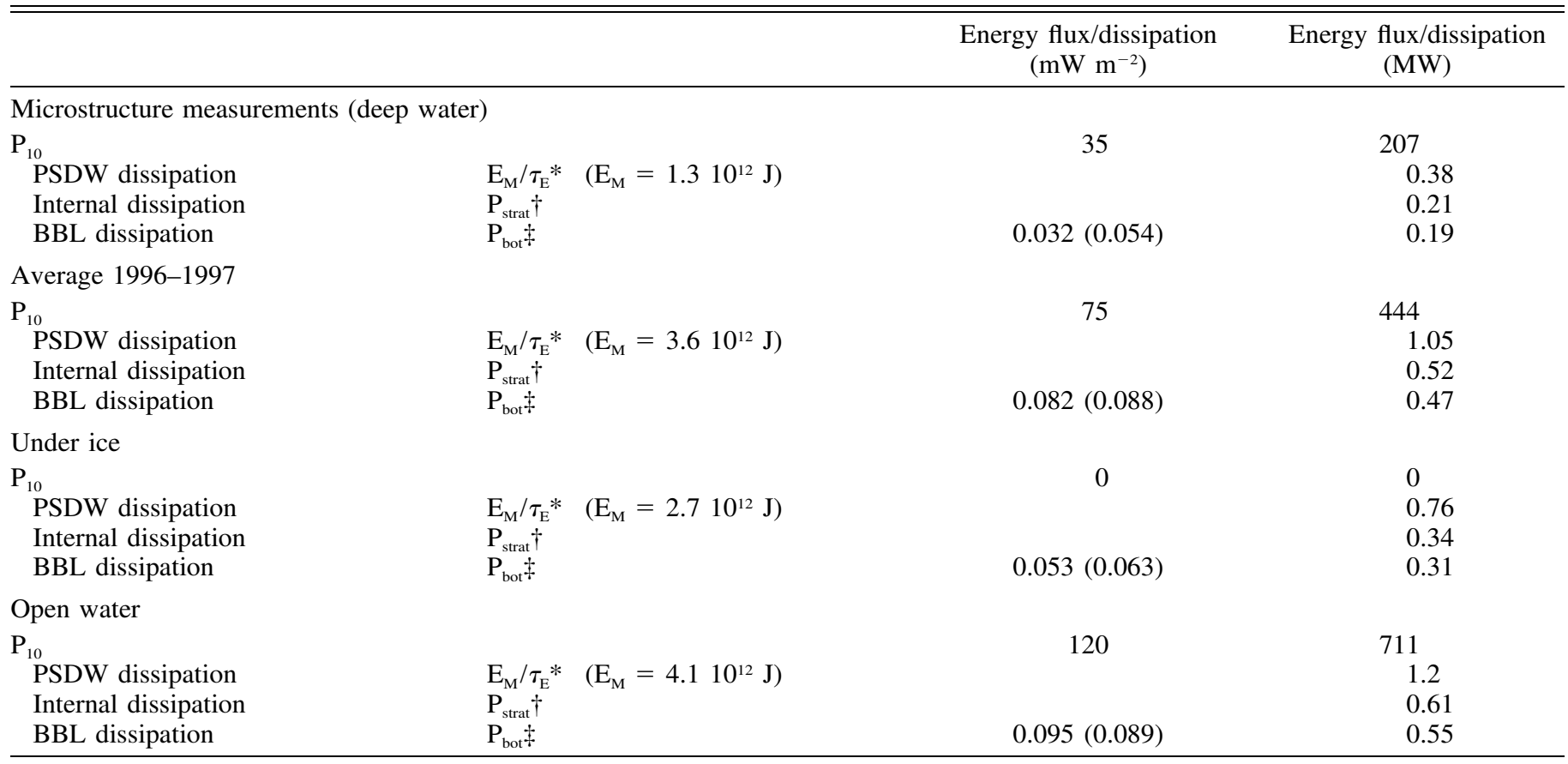

$* \tau_{\mathrm{E}}=40 \mathrm{~d} . \mathrm{E}_{\mathrm{M}}\left(=0.5 \mathrm{M} \mathrm{U}^{2}\right)$ estimate is based on near-bottom velocity (ADV) data and PSDW mass of $4.6310^{12} \mathrm{~kg}$.

$\dagger$ Based on measured and estimated dissipation between 250-m depth and BBL (Table 5).

\$ Estimated from the BBL dissipation estimate, $\mathrm{P}_{\text {bot }}$ in Tables 3 or 5 . The parenthetic data in the second column indicate how the estimate would change if the logarithmic layer extended only to $4 \mathrm{~m}$ above bottom. The total [MW] estimate is based on a south basin bottom surface area of 5,919 $\mathrm{km}^{2}$. Note that with the latter estimate, the relationship PSDW dissipation $\sim \mathrm{P}_{\text {strat }}+\mathrm{P}_{\text {bot }}$ holds.

half of long term conditions. In addition, open water conditions were twice as energetic as under-ice conditions (Table 6). Comparing the 2-y wind power $\mathrm{P}_{10}$ with the PSDW dissipation (including BBL) indicates that $0.2 \%$ of the wind energy flux ends up in the permanently stratified water of Lake Baikal.

\section{Concluding summary}

Based on the analysis of (1) 25 temperature microstructure profiles of 600-m depth, (2) near-bottom currents, as well as (3) daily near-bottom current bursts (sampled at $1 / 3 \mathrm{~Hz}$ ), both collected at the deepest location in the south basin for over 2 years, (4) monthly CTD profiles, and (5) daily wind velocity, we draw the following conclusions with respect to small-scale turbulence and diffusive mixing in the PSDW in Lake Baikal's south basin:

(1) Due to the pressure-dependence of the temperature of maximum density and the constraining influence of the heat fluxes, the water column below $\sim 250$-m depth is very weakly but permanently stratified $\left(\mathrm{N}^{2} \sim 2 \times 10^{-8} \mathrm{~s}^{-2}\right)$. In the PSDW small-scale turbulence is responsible for the diffusive-type vertical fluxes, which compensates the advectivetype ones caused by deep-water intrusions.

(2) The energy for turbulent mixing stems nearly entirely from wind transferring momentum at the inertial scale ( $\mathrm{f} \sim$ $\left.1.6 \mathrm{~d}^{-1}\right)$ into the lake during the period of open water $(260$ d per annum). Only $0.2 \%$ of the observed mean $\mathrm{P}_{10} \sim 75$
$\mathrm{mW} \mathrm{m} \mathrm{m}^{-2}$ reached the PSDW, a value which is also typical for much shallower stratified waters.

(3) Interior turbulence (away from bottom boundaries), measured during 2 weeks when turbulence was generally a factor 2 below average, decayed exponentially as a function of depth (e-folding scale $\sim 180 \mathrm{~m}$ ) below $100 \mathrm{~m}$. At $105 \mathrm{~m}$ above bottom, internal turbulence followed the seasonal wind forcing, reaching the maximum before ice build-up and the minimum at the end of the ice cover. The temporallyaveraged and vertically integrated PSDW interior dissipation (excluding the BBL) would be $\sim 0.1 \mathrm{~mW} \mathrm{~m}^{-2}$, which is about one third of the dissipation measured in the ocean thermocline (Gregg and Sanford 1988). Our non-integrated dissipation estimates $\left(\sim 10^{-9} \mathrm{~W} \mathrm{~kg}^{-1}\right.$ at $100 \mathrm{~m}$ and $\sim 10^{-10}$ W kg ${ }^{-1}$ between 300- and 600-m depth) also corresponded well with the ocean measurements $\left(\sim 1-2 \times 10^{-9} \mathrm{~W} \mathrm{~kg}^{-1}\right.$ at $100 \mathrm{~m}$ and $\sim 1.5 \times 10^{-10} \mathrm{~W} \mathrm{~kg}^{-1}$ at $\left.1000 \mathrm{~m}\right)$ though the decay of dissipation with depth was clearly slower in the ocean. In addition, our interior estimates (between $10^{-9}$ and $10^{-10} \mathrm{~W} \mathrm{~kg}^{-1}$ ) are consistent with offshore Mono Lake thermocline data (MacIntyre et al. 1999), interior (below $10 \mathrm{~m}$ ) Lake Alpnach data (Wüest et al. 1996), and Lake Constance data under low wind forcing (Kocsis et al. 1998). Finally, the average dissipation $\epsilon \sim 10^{-10} \mathrm{~W} \mathrm{~kg}^{-1}$ in a stratification of $\mathrm{N}^{2} \sim 2 \times 10^{-8} \mathrm{~s}^{-2}$ implies active-or even isotropicturbulence $\left(\epsilon \sim 100 \times\left(25 \nu \mathrm{N}^{2}\right)\right.$; Gargett et al. 1984) with huge overturning eddies (Ozmidov scale $\left(\epsilon \mathrm{N}^{-3}\right)^{1 / 2} \sim 5 \mathrm{~m}$ ).

(4) By applying Eq. (5) to the microstructure dissipation 
rates of TKE and of temperature variance, we inferred a mixing efficiency (i.e., the rate of change of potential energy per dissipation) of $\gamma_{\text {mix }} \sim 0.16 \pm 0.1$. Even though this value is uncertain due to the limited number of microstructure profiles, $\gamma_{\text {mix }} \sim 0.16$ is among the values determined from other microstructure data. It is noteworthy that $\gamma_{\text {mix }}$ measured in very weakly stratified water is not different from that obtained from more stratified natural waters.

(5) Currents, measured $4 \mathrm{~m}$ above lake sediment, behaved as those of smooth flow in a logarithmic BBL and indicated a drag coefficient of $\mathrm{C}_{4 \mathrm{~m}} \sim 1.6 \pm 0.2 \times 10^{-3}$ (corresponding to $\mathrm{C}_{1 \mathrm{~m}} \sim 2.3 \pm 0.2 \times 10^{-3}$ ). The bottom current speed $\mathrm{U}_{4 \mathrm{~m}}$ as well as dissipation within the BBL (averaging to $\mathrm{P}_{\mathrm{bot}} \sim$ $0.08 \mathrm{~mW} \mathrm{~m}^{-2}$ ) followed the seasonal pattern revealing twice as much dissipation during open water conditions as during periods of ice-cover.

(6) During the period of microstructure measurements, dissipation in the interior $(207 \mathrm{~kW})$ and within the BBL (189 $\mathrm{kW}$ ) suggest that both processes contribute $\sim 50 \%$ to the total production of turbulence within the PSDW. This observation corroborates with observations in deep waters of ocean basins (Ledwell and Bratkovich 1995; Ledwell and Hickey 1995) as well as in lakes (Goudsmit et al. 1997; MacIntyre et al. 1999), emphasizing the increasing importance of boundary turbulence for diapycnal mixing at large depth.

(7) The PSDW averages of dissipation and kinetic energy provide an energy residence time of $\tau_{\mathrm{E}}=40 \mathrm{~d}$, in agreement with the damping time scales of $38 \pm 2$ and $42 \pm 3 \mathrm{~d}$ determined from the decay of current kinetic energy and dissipation, respectively, under ice. The consistent estimates of the rate of dissipation by means of two different methods indicate that the TKE sinks (interior and boundary) are correctly identified and quantified. During the $103 \pm 3 \mathrm{~d}$ of ice cover, the kinetic energy and speed were respectively reduced by $92 \%$ and $70 \%$.

(8) Applying PSDW-average quantities of dissipation, mixing efficiency, and stability of $\epsilon \sim 2.3 \times 10^{-10} \mathrm{~W} \mathrm{~kg}^{-1}$ (based on a total PSDW dissipation of $1050 \mathrm{~kW}$ and a basin volume (below $250 \mathrm{~m}$ ) of $4628 \mathrm{~km}^{3}$ ), $\gamma_{\text {mix }} \sim 0.16$ and $\mathrm{N}^{2} \sim$ $2 \times 10^{-8} \mathrm{~s}^{-2}$, respectively to Eq. 4 yields a diapycnal diffusivity of $\sim 20 \times 10^{-4} \mathrm{~m}^{2} \mathrm{~s}^{-1}$. The vertical structure of $\mathrm{K}_{\mathrm{z}}$ within PSDW is uncertain, but it is evident, that $\mathrm{K}_{\mathrm{z}}$ has two maxima: one at the upper end of the PSDW (at 250-m depth, where internal turbulence is at maximum; $\sim 90 \times 10^{-4} \mathrm{~m}^{2}$ $\mathrm{s}^{-1}$ ) and one in the deepest layer (where sediment area per volume is largest). In between (at about 600 to $800 \mathrm{~m}$ ) we expect $\mathrm{K}_{\mathrm{z}}$ to have a minimum of $\sim 10 \times 10^{-4} \mathrm{~m}^{2} \mathrm{~s}^{-1}$ ). Since sediment area per volume increases with depth, BBL turbulence dominates interior turbulence below $\sim 800 \mathrm{~m}$.

(9) The range of $10-90 \times 10^{-4} \mathrm{~m}^{2} \mathrm{~s}^{-1}$ for the vertical diffusivity in the upper part of the PSDW is backed up by two different microstructure methods, by the heat balance in this and previous publications $\left(\mathrm{K}_{\mathrm{z}} \cong 10 \times 10^{-4} \mathrm{~m}^{2} \mathrm{~s}^{-1}\right.$; Shimaraev and Granin, 1991), as well as by analysis of the developments of CFCs, tritium, helium and dissolved oxygen profiles (Frank Peeters, pers. comm.). Allowing an uncertainty of a factor of 2-which is realistic given all the insufficiencies of the model assumptions and the data-we conclude without any doubts, that diffusivity within PSDW is 3 orders of magnitude larger than Killworth et al. (1996) estimate.

(10) If the temperature profiles in Lake Baikal south basin were in a quasi-steady state, the diffusive vertical flux of heat $\left(\rho \mathrm{c}_{\mathrm{p}} \mathrm{K}_{\mathrm{z}} \cdot \mathrm{dT} / \mathrm{dz}\right.$; corresponding to $\left.\sim 6 \mathrm{~W} \mathrm{~m}^{-2}\right)$ through the cross sectional area $\mathrm{A} \sim 5919 \mathrm{~km}^{2}$ in $250-\mathrm{m}$ depth must balance the amount of heat replaced in PSDW by the intrusion of water masses per time, $\mathrm{Q}$, intruding at $\Delta \mathrm{T}$ lower temperature; i.e: $A \cdot K_{z} \cdot d T / d z=Q \cdot \Delta T$. Given $K_{z}\left(90 \times 10^{-4}\right.$ $\left.\mathrm{m}^{2} \mathrm{~s}^{-1}\right)$, dT/dz $\left(7 \times 10^{-4} \mathrm{~K} \mathrm{~m}^{-1}\right.$; Fig. 2b), and further assuming $\mathrm{Q}$ to be $10 \%$ of the PSDW per annum (i.e., $\sim 460$ $\mathrm{km}^{3} \mathrm{a}^{-1}$ ) requires that the intruding water masses be $2 \mathrm{~K}$ cooler. However, continuous thermistor recordings in the deepest $100 \mathrm{~m}$ of the south basin (mooring see Fig. 1) show intrusion events with $\Delta \mathrm{T}$ at only about $0.2 \mathrm{~K}$. Probably, some of the cold water intrusions come from exchange with the colder middle basin at the level of the sill $(400 \mathrm{~m})$. Making the heat balance calculation at 400-m depth (where $\mathrm{K}_{\mathrm{z}}=15$ $\times 10^{-4} \mathrm{~m}^{2} \mathrm{~s}^{-1}$ ) yields a $\Delta \mathrm{T}$ of only $0.3 \mathrm{~K}$, in agreement with observations.

Balancing turbulent kinetic energy in the permanently stratified deep water of the south basin allowed us to infer the rate of change of potential energy and turbulent diffusivity despite the extreme conditions (e.g., weak stratification, great depth and ice cover). The turbulence data are consistent with that from other natural waters in completely different physical settings. Despite the fact that Lake Baikal is the largest lake on Earth, the data indicate the dominance of boundary turbulence at great depths (below $800 \mathrm{~m}$ ). The average vertical diffusivity $\sim 20 \times 10^{-4} \mathrm{~m}^{2} \mathrm{~s}^{-1}$, inferred from purely energetic arguments, agree well with tracer-based estimates.

\section{References}

BATCHELOR, G. K. 1959. Small-scale variation of convected quantities like temperature in turbulent fluid. Part 1 . General discussion, and the case of small conductivity, J. Fluid. Mech. 5: 113-133.

Carmack, E. C., And D. M. Weiss. 1991. Convection in Lake Baikal: An example of the thermobaric instability, p.215-228. In P. C. Chu and J. C. Gascard [eds.], Deep convection, and deep water formation in the oceans, Elsevier.

Craig, H. 1989. Helium, tritium, methane, and temperature in deep rift-valley lakes: Tanganyika, Kivu, and Baikal (abstract). EOS Trans. Am. Geophys. Union. 70: 1137.

Dillon, T. M., AND D. R. CALdwell. 1980. The Batchelor spectrum, and dissipation in the upper ocean, J. Geophys. Res. 85: 1910-1916.

Elliott, A. J. 1984. Measurements of the turbulence in an abyssal boundary layer. J. Phys. Oceanogr. 14: 1778-1786.

FARMER, D., AND E. CARMACK. 1981. Wind mixing, and restratification in a Lake near the temperature of maximum density, J. Phys. Oceanogr. 11: 1516-1533.

Gargett, A. E., T. R. Osborn, AND P. W. NASMYth. 1984. Local isotropy, and the decay of turbulence in a stratified fluid. J. Fluid Mech. 144: 231-280.

, AND J. N. Moum. 1995. Mixing efficiencies in turbulent tidal fronts: Results from direct, and indirect measurements of density flux, J. Phys. Oceanogr. 25: 2583-2608.

Gloor, M., O. Kocsis, M. Omlin, M. Schurter, And A. WÜEst. 1995. Temperaturmikrostrukturen, eine Methode zur Bestim- 
mung der Mischungsintensität in geschichteten Gewässern. Gas Wasser Abwasser, 75: 1087-1096.

Golubev, V. A., J. Klerkx, AND R. Kipfer. 1993. Heat flow, hydrothermal vents, and static stability of discharging thermal water in Lake Baikal (south-eastern Siberia), Bull. Centres Rech. Explor. Prod. Elf Aquitaine, 17: 53-65.

Goudsmit, G.-H., F. Peeters, M. Gloor, And A. Wüest. 1997. Boundary versus internal diapycnal mixing in stratified natural waters. J. Geophys. Res. 102: 27,903-27,914.

GregG, M. C., E. A. D'Asaro, T. J. Shay, and N. Larson. 1986. Observations of persistent mixing, and near-inertial internal waves. J. Phys. Oceanogr. 16: 856-885.

, AND T. MEAGHER. 1978. The dynamic response of glass rod thermistors. J. Geophys. Res. 85: 2779-2786.

- , AND T. B. SANFORD. 1988. The dependence of turbulent dissipation on stratification in a diffusively stratified thermocline. J. Geophys. Res. 93: 12381-12392.

Hohmann, R., R. Kipfer, F. Peeters, G. Piepke, and M. N. ShIMARAEV AND D. M. Imboden. 1997. Processes of deep-water renewal in Lake Baikal, Limnol. Oceanogr. 42: 841-855.

- M. Hofer, R. Kipfer, F. Peeters, H. Baur, M. N. ShIMARAEV, AND D. M. IMBODEN. 1998. Distribution of helium, and tritium in Lake Baikal. J. Geophys. Res. 103: 1282312838.

Holloway, P. E. 1980. A criterion for thermal stratification in a wind mixed system. J. Phys. Oceanogr. 10: 861-869.

IMBERGER, J. 1985. The diurnal mixed layer. Limnol. Oceanogr. 30: 737-770.

Jellison, R., AND J. M. Melack. 1993. Meromixis in hypersaline Mono Lake, California. 1. Stratification, and vertical mixing during the onset, persistence, and breakdown of meromixis. Limnol. Oceanogr. 38: 1008-1019.

Killworth, P. D., E. C. CARMack, R. F. Weiss, and R. Matear. 1996. Modeling deep water renewal in Lake Baikal, Limnol. Oceanogr. 41: 1521-1538.

Kocsis, O., B. Mathis, M. Gloor, M. Schurter, and W. WÜest. 1998. Enhanced mixing in narrows: a case study at the Minau sill (Lake Constance). Aquat. Sci. 60: 236-252.

- H. Prandke, A. Stips, A. Simon, and A. Wüest. 1999. Comparison of dissipation of turbulent kinetic energy determined from shear, and temperature microstructure, J. Mar. Syst. 21: $67-84$.

Ledwell, J. R., AND A. Bratkovich. 1995. A tracer study of mixing in the Santa Cruz Basin. J. Geophys. Res. 100: 2068120704.

$\longrightarrow$, AND B. M. HICKEY. 1995. Evidence for enhanced boundary mixing in the Santa Monica Basin. J. Geophys. Res. 100: 20,665-20,679.

Macintyre, S., K. M. Flynn, R. Jellison, and J. R. Romero, 1999. Boundary mixing, and nutrient flux in Mono Lake, California. Limnol. Oceanogr. 44: 236-242.

MARTIN, P. 1994. Lake Baikal, Arch. Hydrobiol. Beih. Ergebn. Limnol. 44: 3-11.

Moum, J. N. 1990. The quest for $\mathrm{K}_{\mathrm{p}}$ : Preliminary results from direct measurements of turbulent fluxes in the ocean, J. Phys. Oceanogr. 20: 1980-1984.

- 1996. Efficiency of mixing in the main thermocline. J. Geophys. Res. 101: 12057-12069.

Mudge, T. D., AND R. G. LuECK. 1994. Digital signal processing to enhance oceanographic observations, J. Atmos. Ocean. Tech. 11: $825-836$.
OAKEY, N. S. 1982. Determination of the rate of dissipation of turbulent energy from simultaneous temperature, and velocity shear microstructure measurements, J. Phys. Oceanogr. 12: 256-271.

- 1988. Estimates of mixing inferred from temperature, and velocity microstructure; Proc. $19^{\text {th }}$ Int. Liege Colloquium on Small Scale Mixing in the Ocean.

Osborn, T. 1980. Estimates of the local rate of vertical diffusion from dissipation measurements, J. Phys. Oceanogr. 10: 83-89.

Osborn, T. R., AND C. S. Cox. 1972. Oceanic finestructure, Geophys. Fluid Dyn. 3: 321-345.

Peeters, F., G. Piepke, R. Kipfer, R. Hohmann, and D. M. IMBODEN. 1996. Description of stability, and neutrally buoyant transport in freshwater lakes, Limnol. Oceanogr. 41: 17111724.

Peters, H., AND M. C. GregG. 1988 Some dynamical, and statistical properties of equatorial turbulence, p.185-200. In Smallscale Turbulence, and Mixing in the Ocean, Proc. $19^{\text {th }}$ Int. Liège Colloquium on Ocean Hydrodynamics, J. C. J. Nihoul and B. M. Jamart [eds.] Elsevier.

Powell, T., AND A. JASSBY. 1974. The estimation of vertical eddy diffusivities below the thermocline in Lakes. Water Resour. Res. 10: 191-198.

RoHR, J., AND C. VAN AtTA. 1987. Mixing efficiency in stably stratified growing turbulence, J. Geophys. Res. 92: 5481-5488.

SEABIRD. 1990. Technical Manual for Temperature-Microstructure Probe SBE-11, Bellevue.

ShimaraEv, M. N., AND N. G. Granin. 1991. Temperature stratification, and the mechanism of convection in Lake Baikal. Dokl. Akad SSSR 321: 831-835.

- N. G. Granin, AND A. A. Zhadanov. 1993. Deep ventilation of Lake Baikal due to spring thermal bars, Limnol. Oceanogr. 38: 1068-1072.

- V. I. Verbolov, N. Granin, And P. P. Sherstayankin. 1994. Physical limnology of Lake Baikal: A review. Okayama, Irkutsk.

Terray, E. A., M. A. Donelan, Y. C. Agrawal, W. L. Drennan, K. K. Kahma, A. J. Williams III, P. A. Hwang, and S. A. KITAIGORODSKII. 1996. Estimates of kinetic energy dissipation under breaking waves. J. of Phys. Oceanogr. 26: 792-807.

WALKER, S. J., AND G. R. WATTS. 1995. A three-dimensional numerical model of deep ventilation in temperate lakes, J. Geophys. Res. 100: 22711-22731.

Weiss, R. F., E. C. Carmack, and V. M. Koropalov. 1991. Deepwater renewal and biological production in Lake Baikal, Nature, 349: 665-669.

Wetzel, R. G. 1983. Limnology $2^{\text {nd }}$ edition. Saunders College Publ. Philadelphia, p. 767.

Wüest, A., D. C. Van Senden, J. Imberger, G. Piepke, and M. GLOOR. 1996. Comparison of diapycnal diffusivities measured by tracer, and microstructure techniques, Dyn. Atmos. Oceans 24: 27-39.

WyngaARD, J. C, AND O. R. Cote. 1971. The budget of turbulent kinetic energy, and temperature variance in the atmospheric surface layer. J. Atmo. Sci. 28: 190-201.

YAMAZAKI, H., AND R. LUECK. 1990. Why oceanic dissipation rates are not lognormal, J.1 of Phys. Oceanogr. 20: 1907-1918.

, AND T. R. OsboRn. 1993. Direct estimation of heat flux in the seasonal thermocline, J. Phys. Oceanogr. 23: 503-516.

Received: 23 February 1999

Accepted: 7 September 1999

Amended: 24 September 1999 